\title{
On the Abyssal Circulation in the Glacial Atlantic
}

\author{
Olivier Marchal and William B. Curry \\ Woods Hole Oceanographic Institution, Woods Hole, Massachusetts
}

(Manuscript received 13 August 2007, in final form 25 January 2008)

\begin{abstract}
An inverse method is used to evaluate the information contained in sediment data for the Atlantic basin during the Last Glacial Maximum (defined here as the time interval 18-21 kyr before present). The data being considered are an updated compilation of the isotopic ratios ${ }^{18} \mathrm{O} /{ }^{16} \mathrm{O}\left(\delta^{18} \mathrm{O}\right)$ and ${ }^{13} \mathrm{C} /{ }^{12} \mathrm{C}\left(\delta^{13} \mathrm{C}\right)$ of fossil shells of benthic foraminifera (bottom-dwelling organisms). First, an estimate of the abyssal circulation in the modern Atlantic is obtained, which is consistent with (i) climatologies of temperature and salinity of the World Ocean Circulation Experiment, (ii) observational estimates of volume transport at specific locations, and (iii) the statements of a finite-difference geostrophic model. Second, estimates of water properties ( $\delta^{18} \mathrm{O}$ of equilibrium calcite or $\delta^{18} \mathrm{O}_{\mathrm{c}}$ and $\delta^{13} \mathrm{C}$ of dissolved inorganic carbon or $\delta^{13} \mathrm{C}_{\mathrm{DIC}}$ ) derived from sediment data are combined with this circulation estimate to test their consistency with the modern flow. It is found that more than approximately $80 \%$ of water property estimates $\left(\delta^{18} \mathrm{O}_{\mathrm{c}}\right.$ or $\left.\delta^{13} \mathrm{C}_{\text {DIC }}\right)$ are compatible with the modern flow given their uncertainties. The consistency of glacial $\delta^{13} \mathrm{C}_{\mathrm{DIC}}$ estimates with the modern flow could be rejected after two assumptions are made: (i) the uncertainty in these estimates is $\pm 0.1 \%$ o (this uncertainty includes errors in sediment core chronology and oceanic representativity of benthic $\delta^{13} \mathrm{C}$, which alone appears better than this value on average); and (ii) $\delta^{13} \mathrm{C}_{\text {DIC }}$ in the glacial deep Atlantic was dominated by a balance between water advection and organic $\mathrm{C}$ remineralization. Measurements of $\delta^{13} \mathrm{C}$ on benthic foraminifera are clearly useful, but the current uncertainties in the distribution and budget of $\delta^{13} \mathrm{C}_{\mathrm{DIC}}$ in the glacial Atlantic must be reduced to increase the power of the test.
\end{abstract}

\section{Introduction}

Our understanding of oceanic variability on time scales longer than $\sim 10^{2}$ yr relies on our capability to interpret the marine sediment record. Extracting information about oceanic conditions from sediment data, however, is a daunting task: the data are scarce, available only at the boundaries (seafloor), and suffer from various errors associated with the sediment core chronology and the oceanic representativity of the properties measured in the sediment. Nevertheless, legitimate questions can be asked, such as the extent to which sediment data provide information about elements of the ocean circulation in the geological past. A period of particular interest is the Last Glacial Maximum (LGM), a time interval near $20 \mathrm{kyr}$ before present (20 kyr BP). A recent review suggested that the meridional overturning circulation (MOC) in the Atlantic during the

Corresponding author address: Olivier Marchal, Woods Hole Oceanographic Institution, Woods Hole, MA 02543.

E-mail: omarchal@whoi.edu
LGM was neither extremely sluggish nor an enhanced version of the modern one (Lynch-Stieglitz et al. 2007).

Here we test the null hypothesis (H0) that observations from Atlantic sediments of the LGM are consistent with the modern circulation in the basin. The observations being considered are measurements of two isotopic ratios on calcite shells of benthic foraminifera (bottom-dwelling organisms): the oxygen isotopic ratio ${ }^{18} r={ }^{18} \mathrm{O} /{ }^{16} \mathrm{O}$ and the carbon isotopic ratio ${ }^{13} r={ }^{13} \mathrm{C} /{ }^{12} \mathrm{C}$. Both ratios are expressed as a relative deviation from a standard ratio, that is, $\delta^{18} \mathrm{O}=\left({ }^{18} r /{ }^{18} r_{s}-1\right) \times 10^{3}$ and $\delta^{13} \mathrm{C}=\left({ }^{13} r /{ }^{13} r_{s}-1\right) \times 10^{3}$, where $\delta^{18} \mathrm{O}$ and $\delta^{13} \mathrm{C}$ are in per mil (\%o). Comparison of each ratio in benthic foraminifera from surface sediments with properties of ambient bottom water showed that the benthic foraminiferal $\delta^{18} \mathrm{O}\left(\delta^{18} \mathrm{O}_{\mathrm{b}}\right)$ varies with water $\delta^{18} \mathrm{O}$ and temperature $\left(\delta^{18} \mathrm{O}_{\mathrm{w}}\right.$ and $\left.T\right)$, whereas the benthic foraminiferal $\delta^{13} \mathrm{C}\left(\delta^{13} \mathrm{C}_{\mathrm{b}}\right)$ varies with the $\delta^{13} \mathrm{C}$ of dissolved inorganic carbon $\left(\delta^{13} \mathrm{C}_{\text {DIC }}\right)$ (Figs. $\left.1-2\right)$ :

$$
\delta^{18} \mathrm{O}_{\mathrm{b}}=3.35+0.97 \delta^{18} \mathrm{O}_{\mathrm{w}}-0.21 T \quad(R=0.98, n=91),
$$

DOI: $10.1175 / 2008 J P O 3895.1$ 


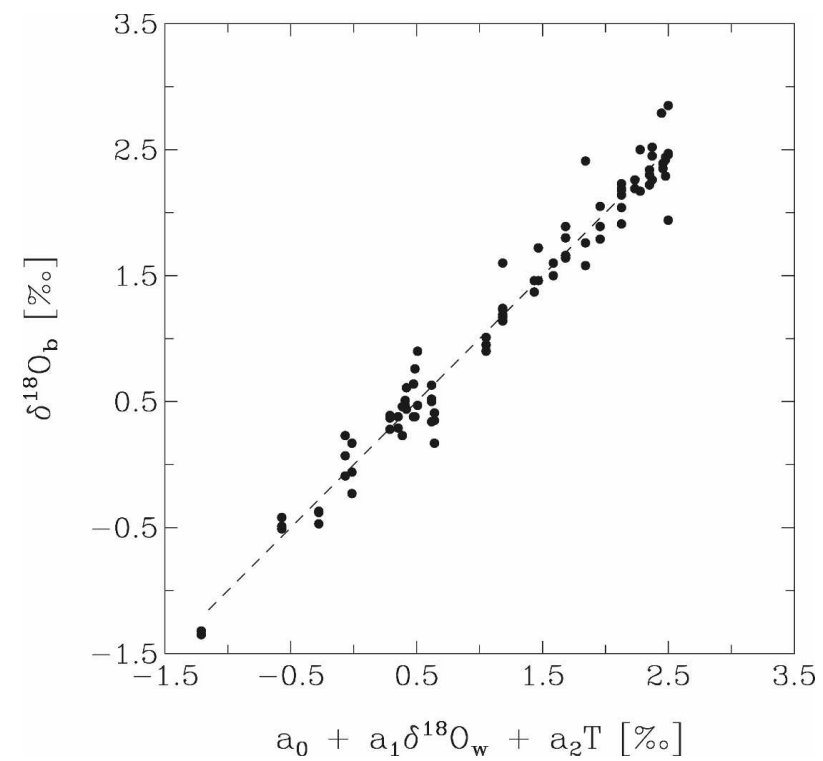

FIG. 1. The $\delta^{18} \mathrm{O}$ of Cibicidoides and Planulina shells sampled from surface sediments vs a linear combination of $\delta^{18} \mathrm{O}$ and in situ temperature of ambient water. The data originate from different depths (53-1535 m) at the Little Bahama Bank (Lynch-Stieglitz et al. 1999). They consist of (i) the averages of replicate $\delta^{18} \mathrm{O}_{\mathrm{b}}$ measurements and (ii) the estimates of water $\delta^{18} \mathrm{O}$ and $T$ at the sediment core water depths from observations at a "nearby" hydrographic station. The values of the coefficients $a_{0}=3.35 \%, a_{1}=$ 0.97 , and $a_{2}=-0.21 \%{ }^{\circ} \mathrm{C}^{-1}$ are obtained by multiple regression (based on the $\delta^{18} \mathrm{O}_{\mathrm{b}}$ averages). The dashed line is the least squares fit $(R=0.98, n=91)$.

$$
\delta^{13} \mathrm{C}_{\mathrm{b}}=0.13+0.90 \delta^{13} \mathrm{C}_{\mathrm{DIC}} \quad(r=0.94, n=67) .
$$

Equation (1) is based on a multiple regression of observations on the benthic foraminiferal genera Cibicidoides and Planulina from sediments of the Little Bahama Bank (depth range 53-1535 m; Lynch-Stieglitz et al. 1999). Note that regression (1) describes the joint influence of $\left(\delta^{18} \mathrm{O}_{\mathrm{w}}, T\right)$ on $\delta^{18} \mathrm{O}_{\mathrm{b}}$, in contrast to the simple regression of the form $\delta^{18} \mathrm{O}_{\mathrm{b}}-\delta^{18} \mathrm{O}_{\mathrm{w}}=f(T)$, which is more common in paleoceanography (e.g., Lynch-Stieglitz et al. 1999). A major difference between the two regressions is that the first one does not presume (e.g., on theoretical grounds) that a unit change of $\delta^{18} \mathrm{O}_{\mathrm{w}}$ causes a unit change of $\delta^{18} \mathrm{O}_{\mathrm{b}}$ at fixed temperature; the closeness of the regression coefficient for $\delta^{18} \mathrm{O}_{\mathrm{w}}$ to 1 [Eq. (1)] actually provides an empirical test of this presumption. Equation (2) is based on a simple regression of observations on the genus Cibicidoides from sediments originating from different oceanic basins (depth range 1000-4181 m; Duplessy et al. 1984). Thus, for the aforementioned taxa, $96 \%$ of the variance in $\delta^{18} \mathrm{O}_{\mathrm{b}}$ would be due to variations in $\delta^{18} \mathrm{O}_{\mathrm{w}}$ and $T$, whereas $88 \%$ of the variance in $\delta^{13} \mathrm{C}_{\mathrm{b}}$ would be due to variations in $\delta^{13} \mathrm{C}_{\mathrm{DIC}}$. Note that such high cor-

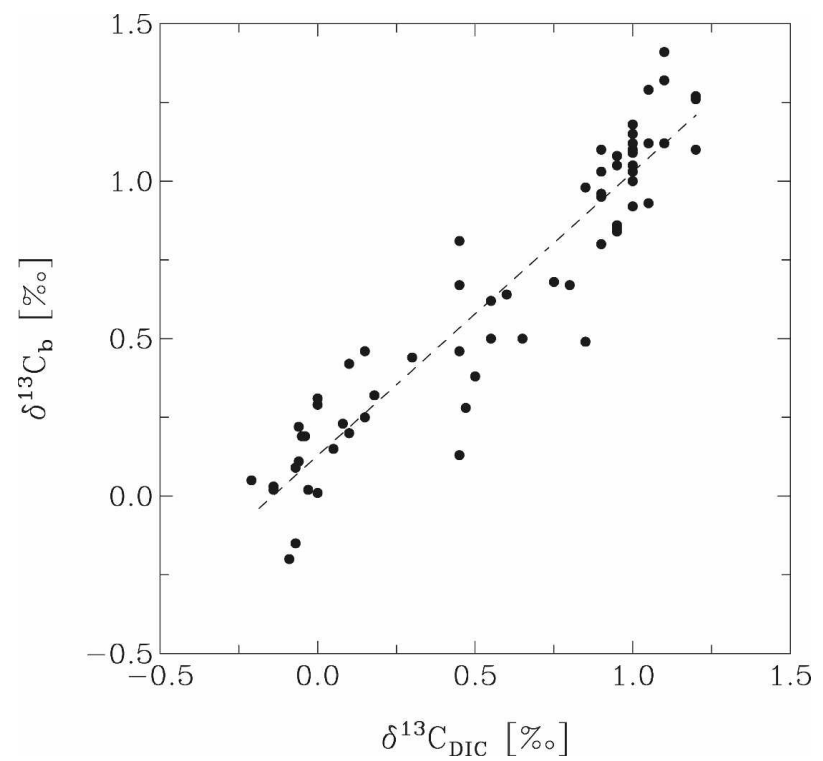

FIG. 2. The $\delta^{13} \mathrm{C}$ of Cibicidoides shells sampled from surface sediments vs $\delta^{13} \mathrm{C}$ of dissolved inorganic carbon of ambient water. The data originate from different depths (1000-4181 m) and different ocean basins (Duplessy et al. 1984). The dashed line is the least squares fit $(r=0.94, n=67)$.

relations do not occur everywhere in the ocean. For example, the difference between $\delta^{13} \mathrm{C}_{\mathrm{b}}$ of Cibicidoides and $\delta^{13} \mathrm{C}_{\mathrm{DIC}}$ of ambient water has been shown to exhibit strong variations at some locations in the eastern South Atlantic (e.g., Mackensen et al. 1993).

The observation that the benthic foraminiferal $\delta^{18} \mathrm{O}$ and $\delta^{13} \mathrm{C}$ reflect generally bottom water properties suggests that measurements of these ratios on fossil shells could constrain the same properties and hence the distribution of water masses in the past. For example, in the modern Atlantic, the North Atlantic Deep Water (NADW) is characterized by $\delta^{13} \mathrm{C}_{\mathrm{DIC}} \geq 1 \%$, whereas the Antarctic Bottom Water (AABW) is characterized by $\delta^{13} \mathrm{C}_{\mathrm{DIC}} \sim 0.4 \%$ o (Kroopnick 1985). Thus, data of benthic foraminiferal $\delta^{13} \mathrm{C}$ from Atlantic sediments are often interpreted in terms of the distribution of water masses originating from the Northern and Southern Hemispheres. The most recent data compilation has been taken to imply the existence in the glacial Atlantic of a southern source water at $\sim 1000 \mathrm{~m}$ (with low $\delta^{13} \mathrm{C}_{\text {DIC }}$ ), a northern source water at $\sim 1500 \mathrm{~m}$ (high $\left.\delta^{13} \mathrm{C}_{\mathrm{DIC}}\right)$, and a southern source water below $2000 \mathrm{~m}$ (low $\delta^{13} C_{\text {DIC }}$; Curry and Oppo 2005).

Inverse methods have been applied in a few studies to interpret sediment data in a dynamically consistent manner (LeGrand and Wunsch 1995, hereafter LW95; Winguth et al. 2000; Gebbie and Huybers 2006). LW95 concluded that the available benthic $\delta^{18} \mathrm{O}$ and $\delta^{13} \mathrm{C}$ data for the LGM were consistent with any flux of Lower 
NADW in the North Atlantic. Winguth et al. (2000) showed that data of benthic $\delta^{13} \mathrm{C}$ and cadmium-tocalcium ratio are compatible with a southward flux of NADW that was shallower during the LGM (the Cd/Ca ratio of benthic foraminifera covaries positively with water Cd concentration, which today is small in NADW and high in AABW; Boyle 1992). However, they did not investigate whether another ocean state-without a similar shallowing of NADW-would also be consistent with these data. Gebbie and Huybers (2006) showed that $\delta^{18} \mathrm{O}$ data of benthic foraminifera of glacial age along the western and eastern margins of the South Atlantic can be explained by a shift in water mass properties without any change in the meridional circulation. Alternatively, they showed that these data would require a circulation different from the modern after several assumptions are made.

LW95 argued that data of benthic foraminiferal $\delta^{18} \mathrm{O}$ and $\delta^{13} \mathrm{C}$ cannot constrain the rates of water motion. In oceanic regions where $\delta^{18} \mathrm{O}_{\mathrm{w}}$ increases with salinity (e.g., Bigg and Rohling 2000), the foraminiferal $\delta^{18} \mathrm{O}$ would covary positively with water density [Eq. (1)], which is dynamically linked to the circulation. However, the relation between $\delta^{18} \mathrm{O}_{\mathrm{w}}$ and salinity is largely unknown for the glacial Atlantic (for emerging evidence, see Adkins et al. 2002), implying that the relation between benthic foraminiferal $\delta^{18} \mathrm{O}$ and bottom water density is also unknown. The very poor constraints on the distribution of density in the glacial ocean severely limits our capability to infer quantitative information about the circulation at the time (LW95; Gebbie and Huyber 2006).

In their analysis of $\delta^{13} \mathrm{C}_{\mathrm{b}}$ data, LW95 treated $\delta^{13} \mathrm{C}_{\mathrm{DIC}}$ as a conservative tracer and argued that the quasiconservative nature of $\delta^{13} \mathrm{C}_{\mathrm{DIC}}$ also prevents this tracer from providing information about the rates of water motion. However, the $\delta^{13} \mathrm{C}_{\text {DIC }}$ of deep waters is not strictly conservative as it tends to decrease because of the remineralization of ${ }^{13} \mathrm{C}$-poor organic matter exported from the upper ocean in dissolved and particulate forms. Simple arguments illustrate the fundamental effects of the neglect of a tracer source (or sink) in the estimation of a fluid flow. Consider first qualitative effects. The transport equation of a nonconservative tracer in the steady state and nondiffusive limits is

$$
\mathbf{u} \cdot \nabla C=J,
$$

where $\mathbf{u}$ is the vector velocity, $C$ is the tracer concentration, and $J$ is the source (or sink) term. Assuming that the tracer is conservative $(J=0)$, the imposition of (3) in the flow estimation would lead to the inference of a velocity perpendicular to the tracer gradient at each point of the fluid. Assuming that the tracer is noncon- servative $(J \neq 0)$, the imposition of (3) would lead to the inference of a different angle between $\mathbf{u}$ and $\nabla C$. Thus, the flow fields inferred in these two cases should exhibit qualitative differences. Then consider quantitative effects. If the fluid is incompressible $(\boldsymbol{\nabla} \cdot \mathbf{u}=0)$, the transport Eq. (3) can be written as

$$
\boldsymbol{\nabla} \cdot(\mathbf{u} C)=J .
$$

The imposition of (4) would force the divergence of the tracer flux $\mathbf{u} C$ to vanish if the tracer is treated as conservative and to equal $J$ if it is treated as nonconservative. In both cases, the velocity field is unbounded unless other constraints on the flow are used, as it can be shown by integrating (4) over an arbitrary volume $V$,

$$
\int_{S} C \mathbf{u} \cdot \hat{n} d S=\int_{V} J d V,
$$

where $\hat{n}$ is an outward unit vector at each point of the surface $S$ enclosing $V$. In both cases $(J=0$ and $J \neq 0)$, the integral of the flux component $C \mathbf{u} \cdot \hat{n}$ is constrained but not the actual distribution of $\mathbf{u}$ over the surface (unless knowledge about $\mathbf{u}$ over the surface is available). On the other hand, a state of rest $(\mathbf{u}=0)$ is a possible solution of (3)-(5) if $J=0$, whereas it is not if $J \neq 0$. These simple arguments stimulate interest in exploring the role of nonconservative tracers in inferences about the ocean circulation (for an application to modern oceanography, see, e.g., Marchal et al. 2007).

Our study extends in several respects earlier applications of inverse methods to paleoceanography. The domain of investigation is the whole Atlantic basin (between $46^{\circ} \mathrm{S}-64^{\circ} \mathrm{N}$ and $1000-4750 \mathrm{~m}$ ) and a larger sediment database is used. The effects of the nonconservative nature of $\delta^{13} \mathrm{C}_{\mathrm{DIC}}$ in the interpretation of benthic foraminiferal $\delta^{13} \mathrm{C}$ data are explored. The hypothesis of a consistency with the modern flow of data from both glacial and postglacial sediments is examined. Whereas a better consistency is expected for postglacial data than for glacial data, this to our knowledge has never been investigated. Assumptions in the data analysis are identified, which leads to accepting the alternative hypothesis that the glacial data are incompatible with the modern circulation. Finally, locations in the abyssal Atlantic are determined, where sediment data would provide additional information about the circulation.

This paper is organized as follows: section 2 is a brief description of the inverse method used to combine noisy observations with imperfect theory. Some notation is introduced and a formal expression of the two problems addressed in this paper is provided. In section 3 , observations and dynamical constraints are combined to produce an estimate of the abyssal circulation 
in the modern Atlantic. The databases of benthic foraminiferal $\delta^{18} \mathrm{O}$ and $\delta^{13} \mathrm{C}$ are presented and their compatibility with our estimate of the modern circulation is tested in section 4. Our results are discussed in section 5 . We examine the sensitivity of the test to uncertainties in the data analysis and identify locations in the deep Atlantic (i.e., at depths $\geq 1000 \mathrm{~m}$ ), where additional data would increase the probability of correctly rejecting $\mathrm{H} 0$ (power of the test). A summary and an outlook follow in section 6 .

\section{Inverse method}

A two-step approach is adopted to assess the dynamical information contained in the sediment data (e.g., LW95). First, an inverse method is applied to produce an estimate of the abyssal circulation in the modern Atlantic that is consistent with observations and a dynamical model. The role of this circulation estimate is not to supersede earlier estimates but to serve as a reference state for the null hypothesis of a compatibility of the sediment data with the modern flow. Second, the inverse method is used to combine water property estimates derived from the sediment data with the modern flow. If a small adjustment in these estimates is necessary to bring them into consistency with the modern flow, then these estimates would be compatible with this flow (i.e., H0 should be accepted). If a large adjustment is necessary, they would not be compatible (i.e., H0 should be rejected). The adjectives small and large mean in comparison to the errors in water property estimates. Thus, two different problems-inference of modern flow and consistency of paleoceanographic data with this flow-are addressed in this paper.

Both problems are expressed in compact form below. Let us define a state vector $\mathbf{x}$ with prior estimate $\mathbf{x}_{o}$ (i.e., before inversion). For our first problem, the elements of $\mathbf{x}$ are the zonal $(U)$, meridional $(V)$, and vertical $(W)$ components of volume transport, and the in situ density $(\rho)$ at different locations of the model grid. For our second problem, $\mathbf{x}$ includes $(U, V, W)$ and water properties related to $\delta^{18} \mathrm{O}_{\mathrm{b}}$ or $\delta^{13} \mathrm{C}_{\mathrm{b}}$ at different grid locations. For both problems, the elements of $\mathbf{x}_{o}$ are observational estimates of the elements of $\mathbf{x}$. The error covariance matrix, or uncertainty, of $\mathbf{x}_{o}$ is noted $\mathbf{C}_{o}=$ $\left\langle\left(\mathbf{x}-\mathbf{x}_{o}\right)\left(\mathbf{x}-\mathbf{x}_{o}\right)^{\mathrm{T}}\right\rangle$, where $\langle\cdot\rangle$ indicates the expected value and the superscript $\mathrm{T}$ is the transpose. The diagonal elements of $\mathbf{C}_{o}$ are the variances (standard deviations squared) of the components of $\mathbf{x}_{o}$, whereas the off-diagonal elements are the error covariances between these components. Let us then define a set of linear constraints $\mathbf{A x}+\boldsymbol{\epsilon}_{\mathrm{A}}=\mathbf{b}$ with uncertainty $\mathbf{C}_{\mathrm{A}}=$
$\left\langle\boldsymbol{\epsilon}_{\mathrm{A}} \boldsymbol{\epsilon}_{\mathrm{A}}^{\mathrm{T}}\right\rangle$ and a set of nonlinear constraints $\mathbf{f}(\mathbf{x})=\boldsymbol{\epsilon}_{\mathrm{f}}$ with uncertainty $\mathbf{C}_{\mathrm{f}}=\left\langle\boldsymbol{\epsilon}_{\mathrm{f}} \boldsymbol{\epsilon}_{\mathrm{f}}^{\mathrm{T}}\right\rangle$. In our case, these constraints are derived from additional observations and/or the statements of the circulation model. Our two problems consist of finding estimates of $\mathbf{x}$ that minimize the cost function

$$
\begin{aligned}
I= & \left(\mathbf{x}-\mathbf{x}_{o}\right)^{\mathrm{T}} \mathbf{C}_{o}^{-1}\left(\mathbf{x}-\mathbf{x}_{o}\right)+(\mathbf{A x}-\mathbf{b})^{\mathrm{T}} \mathbf{C}_{\mathrm{A}}^{-1}(\mathbf{A x}-\mathbf{b}) \\
& +\mathbf{f}(\mathbf{x})^{\mathrm{T}} \mathbf{C}_{\mathrm{f}}^{-1} \mathbf{f}(\mathbf{x}) .
\end{aligned}
$$

Thus, we seek to find state estimates that satisfy the observations and the constraints given their uncertainties. These observations and constraints are imposed only in the mean square, and our estimates of $\mathbf{x}$ are least squares ones. The cost is minimized using the iterative algorithm of total inversion (Tarantola and Valette 1982) as modified to account for imperfect constraints (Mercier 1986). Here, the initial state assumed in the algorithm is the prior $\mathbf{x}_{o}$. In the course of the inversion, the state adjusts to jointly satisfy the observations and the constraints. The uncertainty of the solution $\tilde{\mathbf{x}}, \mathbf{C} \equiv$ $\left\langle(\mathbf{x}-\tilde{\mathbf{x}})(\mathbf{x}-\tilde{\mathbf{x}})^{\mathrm{T}}\right\rangle$ is given by the uncertainty for the linear case, which is a valid approximation for problems with weak nonlinearity (Tarantola and Valette 1982).

\section{Estimation of modern abyssal flow}

In this section, we describe the observations and the dynamical model used to estimate the abyssal circulation in the modern Atlantic. The inverse method is then applied to produce a circulation estimate that is consistent with the observations and the dynamical constraints. The domain of investigation is the Atlantic basin between $46^{\circ} \mathrm{S}-64^{\circ} \mathrm{N}$ and $1000-4750 \mathrm{~m}$ (Fig. 3). The model grid has a horizontal resolution of $2^{\circ}$ and vertical levels at 1000, 2500, 3750, and $4750 \mathrm{~m}$. The coarse resolution is dictated by several factors, such as the paucity of paleoceanographic data and the computational cost of the inversion. The choice of the vertical levels is not completely arbitrary: (i) each level coincides with a level of the grid of the hydrographic climatology used to constrain the modern flow (section 3a), and (ii) the upper two layers (between 1000 and $3750 \mathrm{~m}$ ) and the bottom layer (3750-4750 m) are dominated (today) by NADW and AABW, respectively.

\section{a. Observations}

Three types of observation are used to constrain the abyssal circulation: (i) the distributions of in situ temperature $(T)$ and salinity $(S)$, (ii) the volume transport at specific locations, and (iii) the integrated meridional transport at different latitudes.

The distributions of annual mean $(T, S)$ are derived 


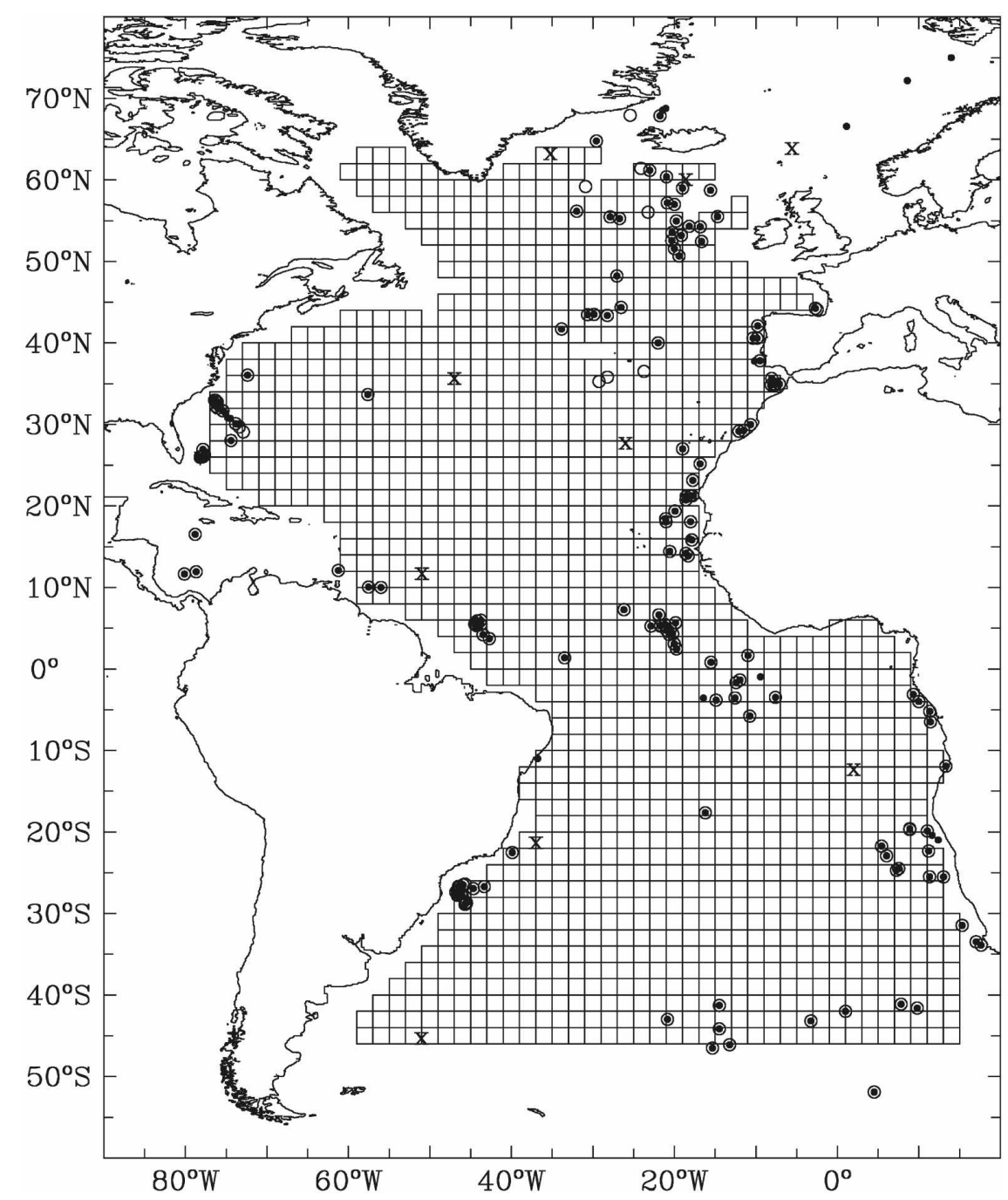

FIG. 3. Location of (i) the sediment cores considered in our compilation of benthic foraminiferal data for the Holocene (solid circles) and LGM (open circles); and (ii) the GEOSECS stations used to illustrate the relation between water density and equilibrium calcite $\delta^{18} \mathrm{O}$ (crosses). The coastline and the model grid (for the layer 1000-2500 m) are also displayed.

from the global hydrographic climatology of the World Ocean Circulation Experiment (WOCE; Gourestki and Koltermann 2004). These authors estimated property distributions at 45 depths on a grid with an approximately $0.5^{\circ} \times 0.5^{\circ}$ resolution. The values of $(T, S)$ at a model grid point are obtained by subsampling the climatologic distributions of $(T, S)$ at depths 1000,2500 , 3750 , and $4750 \mathrm{~m}$. When a point of the model grid does not coincide with a point of the climatologic grid, the climatologic $(T, S)$ values at the closest point are chosen. The $\rho$ values at model grid points are computed from $T, S$, and pressure using EOS80.

The uncertainties of $(T, S)$ at model grid points are obtained by subsampling the distributions of the standard deviations of $(T, S)$ at depths 1000, 2500, 3750, and
$4750 \mathrm{~m}$ as reported in the WOCE atlas (Gourestki and Koltermann 2004). Again, if a model grid point does not coincide with a point of the climatologic grid, the climatologic deviations at the closest point are chosen. To propagate the $(T, S)$ deviations on the density uncertainty, we use a linear equation of state with $\partial \rho / \partial T=$ $-2 \times 10^{-4} \rho_{o} \mathrm{~kg} \mathrm{~m}^{-3}{ }^{\circ} \mathrm{C}^{-1}\left(\rho_{o}=1028 \mathrm{~kg} \mathrm{~m}^{-3}\right.$ is a reference density) and $\partial \rho / \partial S=0.8 \mathrm{~kg} \mathrm{~m}^{-3}$, neglect the pressure error, and assume zero correlation between the $(T, S)$ deviations.

Observational estimates of volume transport at specific locations are used as further constraints on the flow. First, we assume that the western boundary carries a volume transport of $18 \mathrm{~Sv}\left(1 \mathrm{~Sv}=10^{6} \mathrm{~m}^{3} \mathrm{~s}^{-1}\right.$; Plate 7 of Schmitz 1995) between 1000 and $3750 \mathrm{~m}$ 
TABLE 1. Observational estimates of volume transports between 3750 and $4750 \mathrm{~m}$ (AABW). Positive values denote a transport to the east or north; FZ denotes Fracture Zone.

\begin{tabular}{lcccc}
\hline \hline \multicolumn{1}{c}{ Passage } & Lat & Lon & Flux (Sv) & Reference \\
\hline Vema Channel & $28^{\circ} \mathrm{S}$ & $37^{\circ}-39^{\circ} \mathrm{W}$ & +4.0 & Hogg et al. (1999) \\
Hunter Channel & $34^{\circ} \mathrm{S}$ & $27^{\circ}-29^{\circ} \mathrm{W}$ & +2.9 & Zenk et al. (1999) \\
Equatorial Channel & $0^{\circ}-2^{\circ} \mathrm{N}$ & $37^{\circ} \mathrm{W}$ & -2.0 & Hall et al. (1997) \\
Romanche-Chain FZs & $0^{\circ}$ & $19^{\circ}-21^{\circ} \mathrm{W}$ & +1.2 & Mercier and Speer (1998) \\
Vema FZ & $10^{\circ}-12^{\circ} \mathrm{N}$ & $43^{\circ} \mathrm{W}$ & +2.0 & McCartney and Curry (1993) \\
\hline
\end{tabular}

(NADW). The flux east of $40^{\circ} \mathrm{W}$ in the Northern Hemisphere is taken as $4 \mathrm{~Sv}$ (Fig. I-86 of Schmitz 1996). An uncertainty (one standard deviation) of $3 \mathrm{~Sv}$ is assumed for both fluxes. Second, the volume transport across topographic passages between 3750 and $4750 \mathrm{~m}$ (AABW) is constrained (Table 1). An uncertainty of $0.5 \mathrm{~Sv}$ is assumed for each of these fluxes. Finally, the westward transport of Mediterranean Outflow Water (MOW) into the Atlantic is also imposed. We assume a flux of $-2.0 \mathrm{~Sv}$ at $9^{\circ} \mathrm{W}$ between $1000-2500 \mathrm{~m}$ and $36^{\circ}-38^{\circ} \mathrm{N}$, which is in the range of observational estimates of -2.2 Sv (Ochoa and Bray 1991) and -1.9 Sv (Baringer and Price 1997). The uncertainty of this flux is fixed at 0.3 $\mathrm{Sv}$, which is equal to the range of these estimates.

Lastly, we request that our circulation scheme satisfies observational estimates of the zonal and vertical integral of the meridional volume transport at three latitudes (below the depth $1000 \mathrm{~m}$ ). The integrated transports at $24^{\circ}$ and $36^{\circ} \mathrm{N}$ are constrained at $-20 \mathrm{~Sv}$, and the integrated transport at $32^{\circ} \mathrm{S}$ is constrained at $-15 \mathrm{~Sv}$. These values are consistent with estimates based on hydrographic sections across the basin reported by Roemmich and Wunsch (1985) (transports at $24^{\circ}$ and $36^{\circ} \mathrm{N}$ below $\sigma_{\theta}=27.7 \mathrm{~kg} \mathrm{~m}^{-3}$; their Table 1$)$, Talley (2003) (transport at $24^{\circ} \mathrm{N}$ below $\sigma_{\theta}=27.74 \mathrm{~kg}$ $\mathrm{m}^{-3}$, her Table 7 ; transport at $32^{\circ} \mathrm{S}$ below $\sigma_{\theta}=27.4 \mathrm{~kg}$ $\mathrm{m}^{-3}$, her Table 9), and Bryden et al. (2005) (transport at $24^{\circ} \mathrm{N}$ below $1000 \mathrm{~m}$; their Table 1$)$. The uncertainty of each of these fluxes is taken as $3 \mathrm{~Sv}$.

\section{b. Model}

We consider a model of the time-mean flow in the abyssal ocean. The model assumes that the fluid is incompressible and Boussinesq and that the flow is in hydrostatic and geostrophic balance. Diabatic effects appear as a vertical diffusion term in the equation for density. The differential equations of motion are discretized on a grid with horizontal spacing of $2^{\circ}$ and vertical spacing of 1000,1250 , or $1500 \mathrm{~m}$. The variables of the finite-difference model are the densities $(\rho)$ carried by the box corners and the transport components $(U, V, W)$ defined at the box faces. Appendix A de- scribes the difference equations of the model, that is, the statement of volume conservation [Eq. (A.1)], the thermal wind relations (A.2)-(A.3), the linear vorticity balance (A.4), and the density Eq. (A.5).

The residuals $\epsilon_{i}$ in Eqs. (A.1)-(A.5) should account for errors associated with missing physics, the representation of vertical mixing, and the discretization. Volume fluxes in the abyssal ocean are $O\left(10^{6}\right) \mathrm{m}^{3} \mathrm{~s}^{-1}$ in the interior and $O\left(10^{7}\right) \mathrm{m}^{3} \mathrm{~s}^{-1}$ near the western boundary. A small standard deviation is assumed for (A.1), that is, $\left\langle\epsilon_{m}^{2}\right\rangle^{1 / 2}=10^{4} \mathrm{~m}^{3} \mathrm{~s}^{-1}$, which ensures that our circulation estimate is volume conserving to a very good approximation. An important source of error in (A.2)-(A.4) is the geostrophic approximation, which should fail near the equator and the western boundary (e.g., Pedlosky 1996). Here, the constraints (A.2)-(A.4) are not imposed within $\pm 5^{\circ}$ of the equator and the vorticity balance (A.4) is not imposed between 1000 and $3750 \mathrm{~m}$ along the western boundary, where the volume transport of NADW is prescribed (section 3a). Otherwise, we assume $\left\langle\epsilon_{\mathrm{v}}^{2}\right\rangle^{1 / 2}=\left\langle\epsilon_{\mathrm{u}}^{2}\right\rangle^{1 / 2}=\left\langle\epsilon_{\zeta}^{2}\right\rangle^{1 / 2}=10^{6} \mathrm{~m}^{3} \mathrm{~s}^{-1}$. Finally, the standard deviation for the density Eq. (A.5) is fixed at $\left\langle\epsilon_{\rho}^{2}\right\rangle^{1 / 2}=10^{6} \mathrm{~kg} \mathrm{~s}^{-1}$.

\section{c. Flow estimate}

\section{1) Prior state And uncertainties}

The prior state $\left(\mathbf{x}_{o}\right)$ is constructed as follows: the density distribution comes from WOCE climatology (section 3a); the horizontal transports $(U, V)$ are (i) diagnosed from the density distribution and the thermal wind (A.2)-(A.3) assuming an arbitrary level of no motion at $3750 \mathrm{~m}$ or the seafloor if shallower, (ii) prescribed according to observational estimates, or (iii) fixed to $0 \mathrm{~Sv}$. Option (ii) is used along the western boundary and at specific locations of AABW and MOW flows (section 3a). The transports along the western boundary are assigned a prior value of $-9 \mathrm{~Sv}$ (for westward and southward transports) or $+9 \mathrm{~Sv}$ (eastward transport) in each of the two upper layers. East of $40^{\circ} \mathrm{W}$ in the North Atlantic, these transports are $-2 \mathrm{~Sv}$ or $+2 \mathrm{~Sv}$. Option (iii) is used within $\pm 5^{\circ}$ of the equator. The vertical transports $W$ are deduced by con- 
tinuity [Eq. (A.1)] assuming no normal flow at the rigid boundaries, that is, at the bottom and at most of the lateral boundaries.

The error covariance matrices $\left(\mathbf{C}_{o}, \mathbf{C}_{\mathrm{A}}, \mathbf{C}_{f}\right)$ are taken as diagonal. The diagonal elements of $\mathbf{C}_{o}$ are the variances of $(\rho, U, V, W)$ assumed in $\mathbf{x}_{o}$. The standard deviations for $\rho$ are derived from the WOCE atlas (section 3a). The standard deviations for $(U, V, W)$ are equal to $3 \mathrm{~Sv}-$ a relatively large value motivated by the assumptions about a level of no motion and about the prior flow near the equator. Lower values are used at specific locations of AABW and MOW flows (section 3a). The diagonal elements of $\mathbf{C}_{\mathrm{A}}$ are the variances for the integrated meridional transports and the linear Eqs. (A.1)-(A.4) (sections 3a, b), whereas the diagonal elements of $\mathbf{C}_{f}$ are the variances for the nonlinear Eqs. (A.5) (section 3b).

In summary, the prior state $\mathbf{x}_{o}$ satisfies climatologic observations of density, volume conservation, and the thermal wind at most locations. It is used to initialize the inversion. In the course of the inversion, the state should adjust to jointly satisfy all the observations and constraints on the flow. The total number of variables (number of elements of $\mathbf{x}$ ) is 15492 and the total number of equations (constraints) is 12775 , which illustrates the formal underdeterminacy of the estimation problem.

\section{2) Posterior state And uncertainties}

We discuss the flow estimate obtained by combining the prior estimate described above with the other observations and constraints. Earlier inferences of abyssal flows based on inverse methods assumed an implicit (e.g., Vanicek and Siedler 2002) or explicit representation of vertical or diapycnal mixing (e.g., Lumpkin and Speer 2003). In this section, the density Eq. (A.5) is imposed with the vertical mixing term removed $(F=0$; appendix A); the influence of this term on the solution is examined in section $3 \mathrm{~d}$.

The cost function $I$ decreases by two orders of magnitude in one iteration and exhibits, then, minor changes (not shown), suggesting that the problem is nearly linear. To explore the uniqueness of the solution, the inversion is initialized from a different position in the state space. Each element of the initial state is perturbed by a Gaussian deviate with zero mean and unit variance, that is, $x_{o, i} \rightarrow x_{o, i}+\delta \sqrt{C_{o, i}}$, where $\langle\delta\rangle=0$ and $\left\langle\delta^{2}\right\rangle=1$. In this case, the cost converges after about four iterations (not shown). After convergence, the state elements are almost identical to those obtained from the unperturbed initial state (e.g., the rms difference for each transport component averages to less
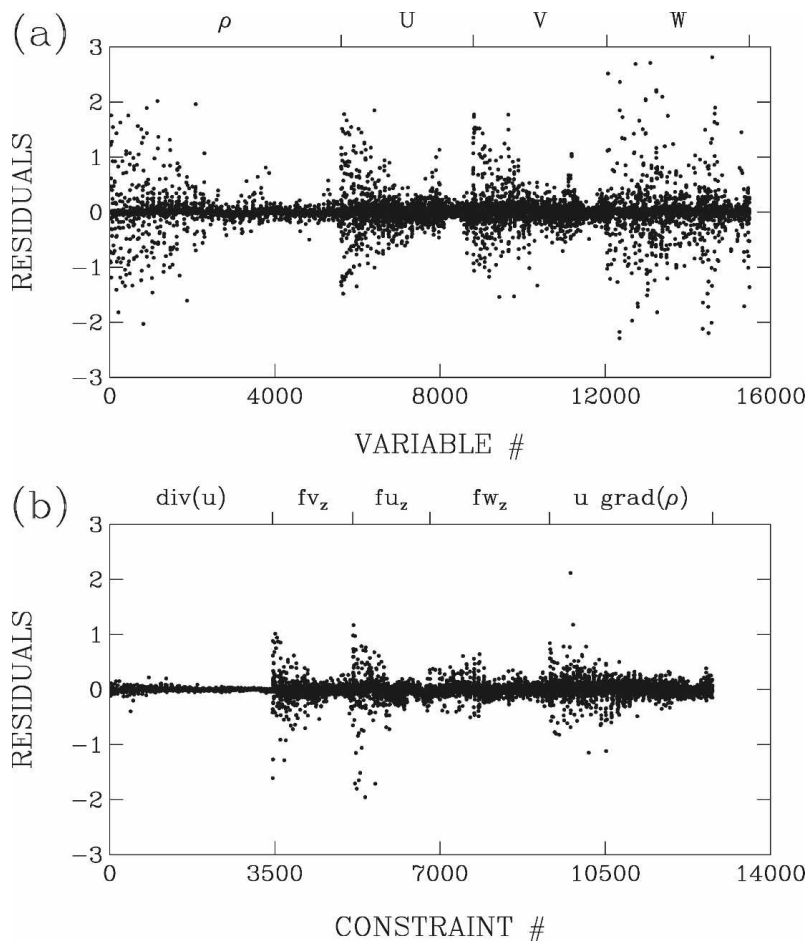

FIG. 4. Diagnostics for the estimation of the modern flow. (a) Normalized residuals for density $(\rho)$ and the three transport components $(U, V, W)$. (b) Normalized residuals for Eqs. (A.1)-(A.5) (see appendix A).

than $10^{-3} \mathrm{~Sv}$ ), suggesting that the solution ( $\tilde{\mathbf{x}}$ below) is stable.

We verify that the flow obtained by inversion satisfies the observations and the dynamical constraints given the prior uncertainties. The diagnostics are the normalized residuals $\left(\tilde{x}_{i}-x_{o, i}\right) / \sqrt{C_{o, i}}$ and $f_{i}(\tilde{\mathbf{x}}) / \sqrt{C_{f, i}}$ (Fig. 4). Less than $5 \%$ of the posterior values of $(\rho, U$, $V, W)$ differ from their prior values by more than two standard deviations, and less than $5 \%$ of the imbalances of Eqs. (A.1)-(A.5) differ from zero by more than two standard deviations. The integrated meridional transports inferred at $36^{\circ} \mathrm{N}, 24^{\circ} \mathrm{N}$, and $32^{\circ} \mathrm{S}$ are compatible with most transatlantic estimates (Fig. 5). Thus, the flow estimate obtained by inversion appears generally consistent with the observations and the dynamical constraints.

Some of the major elements of the estimated flow are touched upon. The upper layer (1000-2500 m) displays the southward current along the western boundary and coherent structures in the interior (Fig. 6). These structures include (i) the eastward flow between $50^{\circ}$ and $55^{\circ} \mathrm{N}$, (ii) the southward and westward motions between $30^{\circ}$ and $50^{\circ} \mathrm{N}$, (iii) recirculating flows from the western boundary such as near $40^{\circ} \mathrm{N}, 10^{\circ} \mathrm{N}$, and $25^{\circ} \mathrm{S}$, and (iv) the zonal transport south of $40^{\circ} \mathrm{S}$, where hori- 


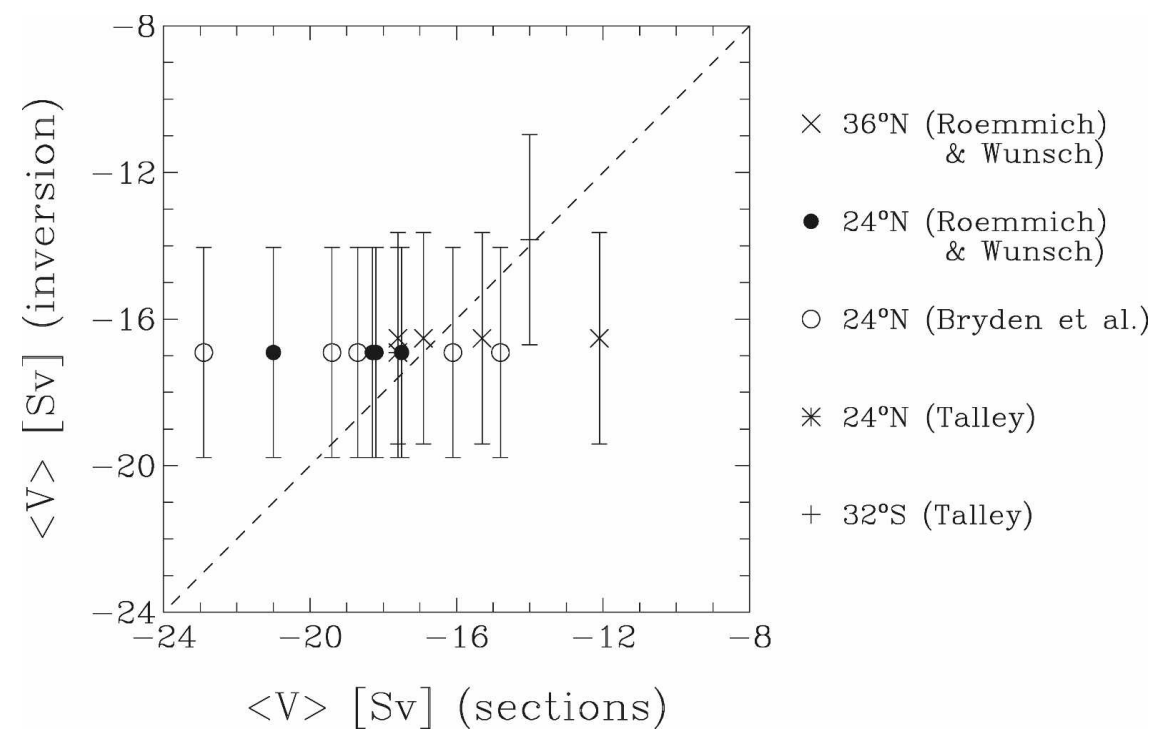

FIG. 5. Comparison between integrated meridional transports below $1000 \mathrm{~m}$ inferred in this study (vertical axis) and estimated from transatlantic sections (horizontal axis). The transatlantic estimates are from Roemmich and Wunsch (1985), Talley (2003), and Bryden et al. (2005). Note that they are among the constraints used to infer the flow. The vertical bars are the std devs for the prior transports $(3 \mathrm{~Sv})$. The dashed line is the line of perfect agreement.

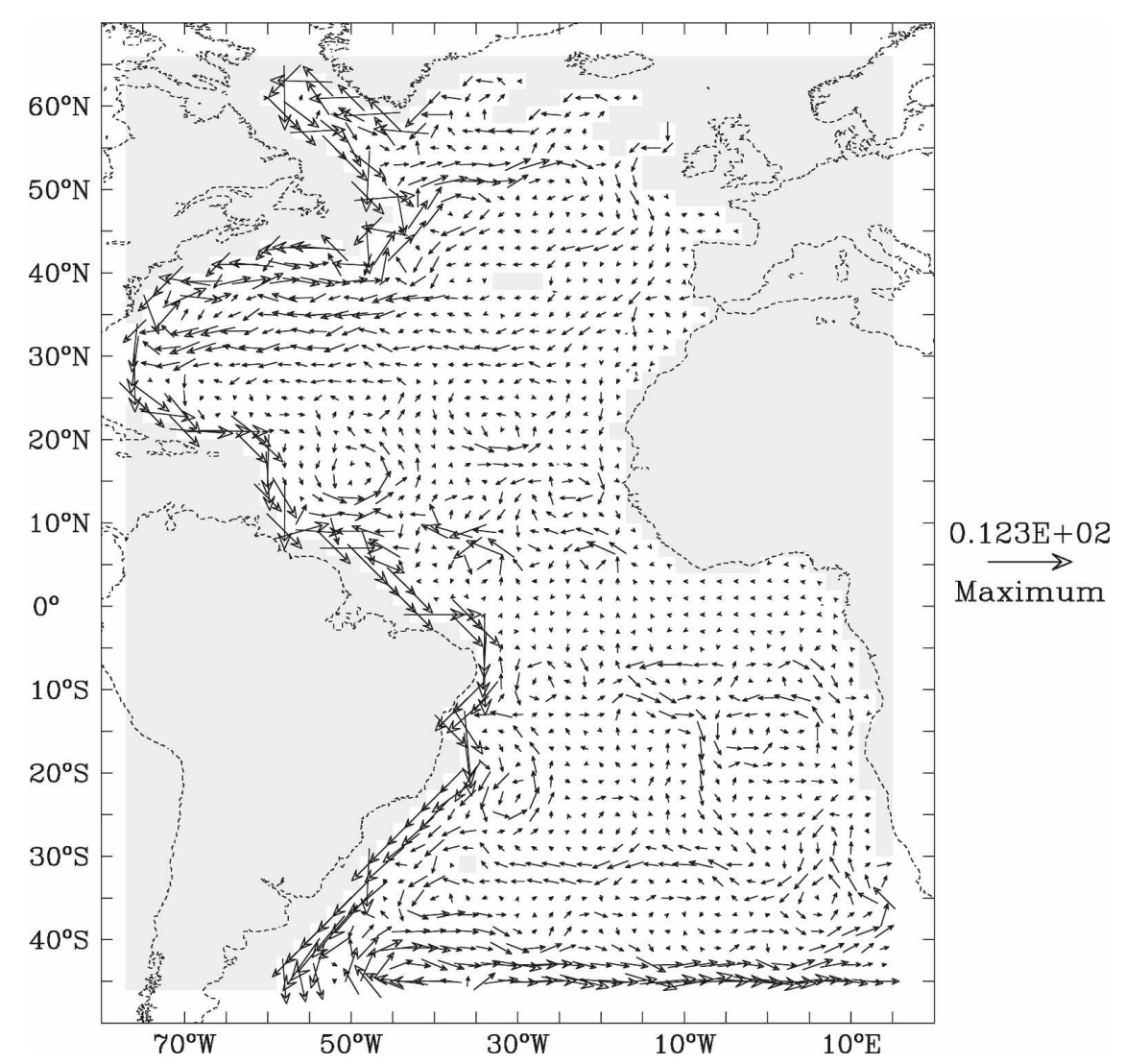

FIG. 6. Distribution of the horizontal transport (Sv) between 1000 and $2500 \mathrm{~m}$ in the modern Atlantic estimated by inversion. The maximum transport in this layer has an amplitude of 12.3 Sv. The dashed line and the shaded areas show the coastline and the model topography, respectively. 


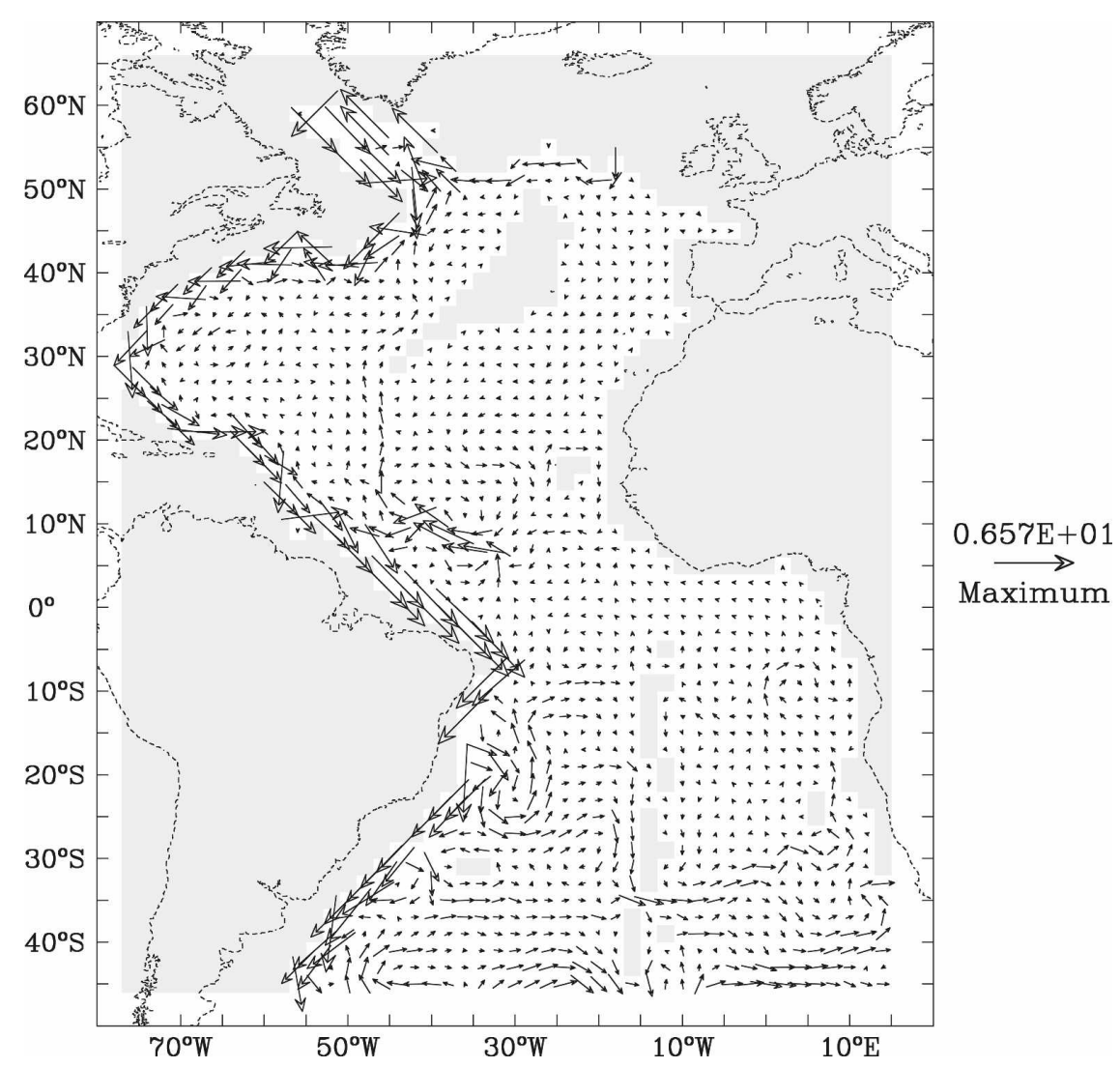

FIG. 7. Distribution of the horizontal transport (Sv) between 2500 and $3750 \mathrm{~m}$ in the modern Atlantic estimated by inversion. The maximum transport shown in this layer has an amplitude of $6.6 \mathrm{~Sv}$ (only transport values $\geq 7 \mathrm{~Sv}$ are displayed to better represent the interior flow). The dashed line and the shaded areas show the coastline and the model topography, respectively.

zontal density gradients are large (not shown). The intermediate layer (2500-3750 m) exhibits a sharper contrast between the vigorous southward current along the western boundary and the relatively sluggish flow in the interior (Fig. 7). Coherent structures, however, are also visible in the interior, such as (i) the northward motion between $10^{\circ}$ and $30^{\circ} \mathrm{N}$ near $45^{\circ} \mathrm{W}$, (ii) the northwestward flow between $5^{\circ}-10^{\circ} \mathrm{N}$ and $35^{\circ}-40^{\circ} \mathrm{W}$ (a structure also visible in the layer above; Fig. 6), (iii) the recirculation from the western boundary between $15^{\circ}$ and $25^{\circ} \mathrm{S}$, (iv) the southward transport along the western flank of the Mid-Atlantic Ridge (MAR) between $20^{\circ}$ and $35^{\circ} \mathrm{S}$, and (v) the zonal motion south of this latitude. Finally, in the bottom layer (3750-4750 m), the transport along the western boundary is southward in the Northern Hemisphere and northward in the Southern Hemisphere (Fig. 8). Conspicuous elements of the flow in the interior are (i) the transport across and downstream of topographic passages, (ii) the eastward motion south of the boundary current between $35^{\circ}$ and $40^{\circ} \mathrm{N}$, (iii) the southward flow east of the boundary current in the Brazil Basin, and (iv) the zonal transport south of $35^{\circ} \mathrm{S}$.

A structure in our flow estimate that shares some similarity with independent observations is the recirculation at the southern edge of the western boundary current near $40^{\circ} \mathrm{N}$. This recirculation is present in all layers (Figs. 6-8). It may correspond to the Northern Recirculation Gyre located seaward of the boundary current and suggested by compilations of long-termed moored current meter data (Hogg 1983; Hogg et al. 1986), although the model resolution is close to the meridional scale of the gyre. According to these authors, the gyre carries a volume flux of $20-40 \mathrm{~Sv}$. This is larger than in the inversion, probably due to the climatologic averaging and the coarse resolution.

We consider the posterior uncertainties in some of the circulation elements discussed above. The posterior uncertainties in the integrated meridional transports at $36^{\circ} \mathrm{N}, 24^{\circ} \mathrm{N}$, and $32^{\circ} \mathrm{S}$ (all equal to $2.9 \mathrm{~Sv}$ ) are only slightly lower than their prior uncertainties (3 Sv), indicating that knowledge of these transports is barely 


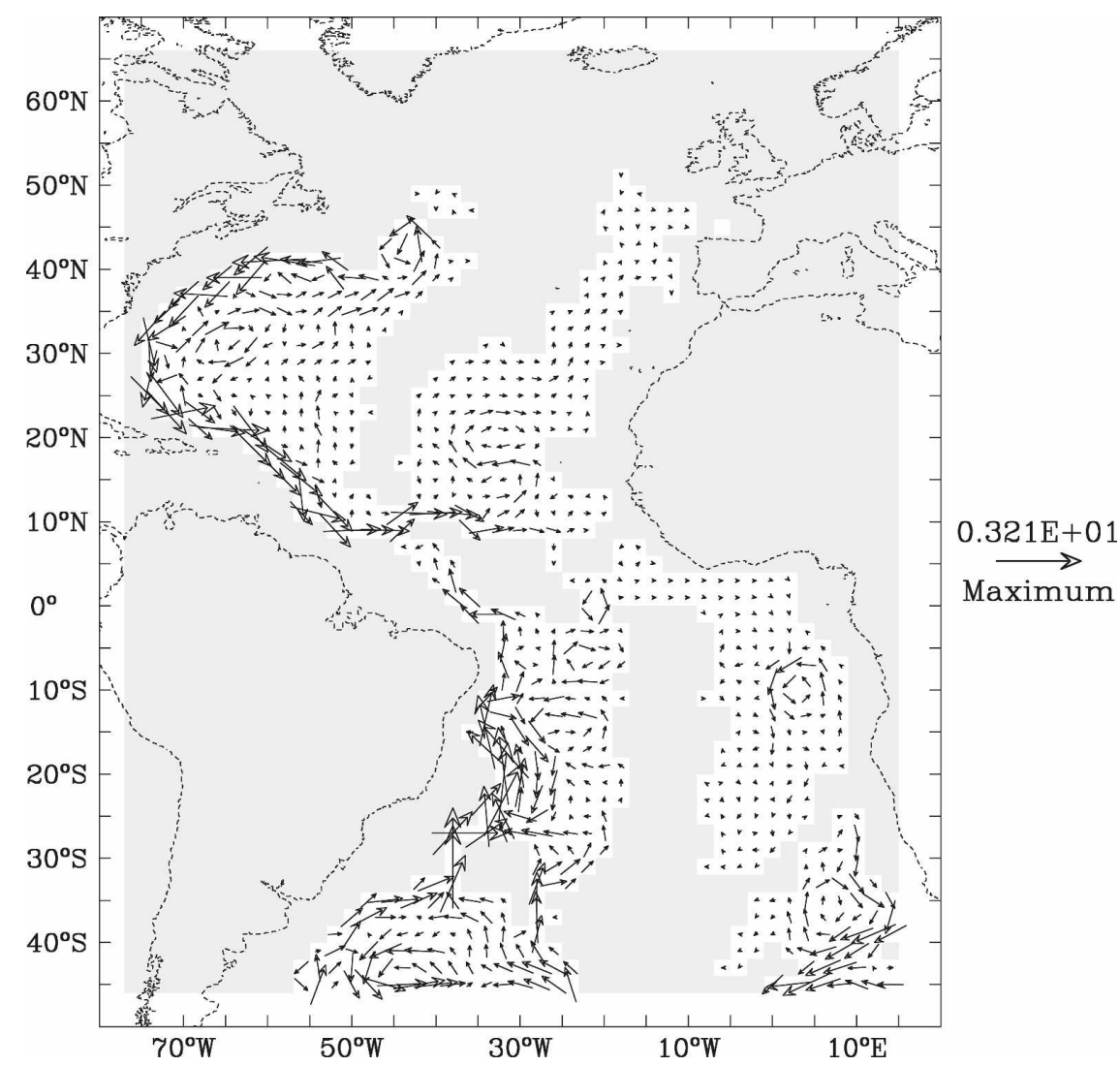

FIG. 8. Distribution of the horizontal transport (Sv) between 3750 and $4750 \mathrm{~m}$ in the modern Atlantic estimated by inversion. The maximum transport in this layer has an amplitude of 3.2 Sv. The dashed line and the shaded areas show the coastline and the model topography, respectively.

improved by the inversion. In contrast, about $70 \%$ of the individual meridional transports at these latitudes has a posterior uncertainty estimated at less than $2 \mathrm{~Sv}$, compared to the prior uncertainty of $3 \mathrm{~Sv}$ (Fig. 9). Thus, the increase in determinacy is larger for the individual transports than for the integrated transports, although the integrated flows-of $O(10) \mathrm{Sv}$-are much better constrained (i.e., most of the posterior uncertainties in Fig. 9 exceed in amplitude the corresponding individual transports). The flow structures in the interior (Figs. 6-8) have a low statistical significance compared to the integrated meridional transports and the western boundary current.

\section{d. Influence of vertical mixing}

The modern flow is now estimated by combining the observations and the statements (A.1)-(A.5) with the vertical mixing term retained explicitly in the density equation [i.e., with $F \neq 0$ in (A.5)]. A standard deviation $\left\langle\epsilon_{\rho}^{2}\right\rangle^{1 / 2}=10^{6} \mathrm{~kg} \mathrm{~s}^{-1}$ is assumed, as for the previous inversion with $F=0$. Again, the cost converges after

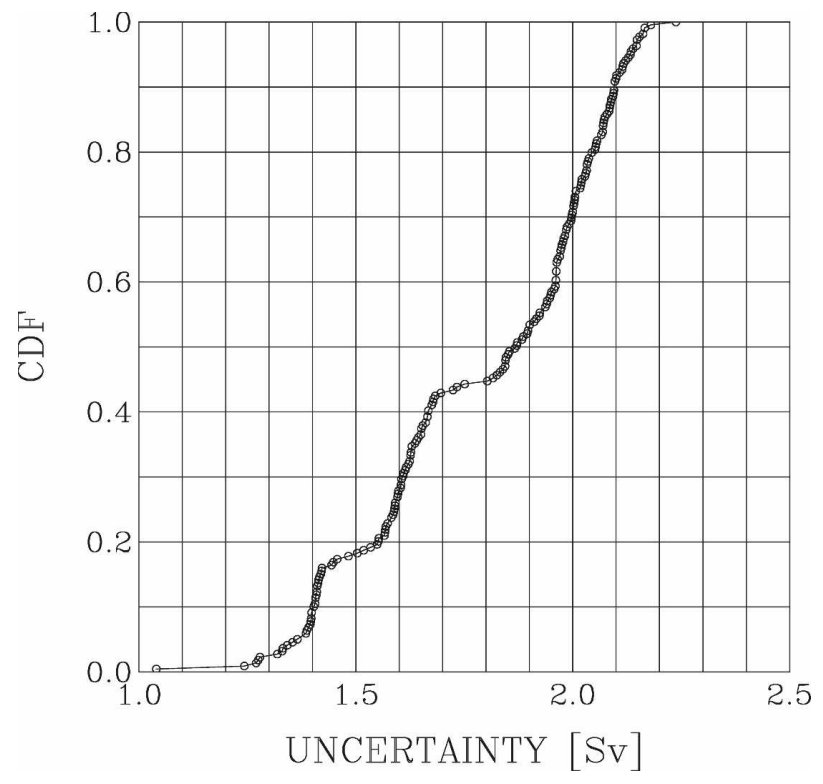

FIG. 9. Cumulative distribution function of the posterior uncertainties in the individual meridional transports at $36^{\circ} \mathrm{N}, 24^{\circ} \mathrm{N}$, and $32^{\circ} \mathrm{S}$. 
about one iteration (not shown). The rms difference between the individual transport components of the solutions with vertical mixing represented explicitly and implicitly averages $1 \times 10^{-3} \mathrm{~Sv}$ for $U, 1 \times 10^{-3} \mathrm{~Sv}$ for $V$, and $4 \times 10^{-4} \mathrm{~Sv}$ for $W$. The difference between the integrated meridional transports is less than $0.2 \mathrm{~Sv}$ at all latitudes.

We examine whether vertical mixing has a larger influence if the density equation is deemed to be more accurate. Two inversions are conducted with $\left\langle\epsilon_{\rho}^{2}\right\rangle^{1 / 2}=$ $10^{5} \mathrm{~kg} \mathrm{~s}^{-1}$ : one with $F=0$ and the other with $F \neq 0$. In this case, the rms difference between the individual transport components of the two solutions averages $5 \times$ $10^{-3} \mathrm{~Sv}$ for $U, 5 \times 10^{-3} \mathrm{~Sv}$ for $V$, and $6 \times 10^{-4} \mathrm{~Sv}$ for $W$. The difference between the integrated meridional transports is less than $0.4 \mathrm{~Sv}$ at all latitudes. Thus, vertical mixing has a relatively minor influence on the estimated flow for $\left\langle\epsilon_{\rho}^{2}\right\rangle^{1 / 2} \geq 10^{5} \mathrm{~kg} \mathrm{~s}^{-1}$. For simplicity, only the inversion with an implicit representation of vertical mixing is considered below.

\section{e. Comparison to earlier estimates}

We summarize earlier estimates of the time-mean flow in the deep Atlantic at resolution(s) comparable to ours based on the combination of observation and theory (appendix B). This short review indicates that a western boundary current is a common feature (here the current is imposed as an observational constraint of the form $\mathbf{A x}+\boldsymbol{\epsilon}_{\mathrm{A}}=\mathbf{b}$ ). In contrast, discrepancies exist regarding flow structures in the interior (e.g., Olbers et al. 1985; Martel and Wunsch 1993). Whether such discrepancies are significant is unclear given the typically large uncertainties for the interior flow (e.g., Fig. 9). Although our circulation estimate is compatible with observations and plausible theory, no claim is made that the time-mean flow inferred here is more accurate than in earlier studies.

\section{Analysis of sediment data}

In this section, the data of benthic foraminiferal $\delta^{18} \mathrm{O}$ and $\delta^{13} \mathrm{C}$ for glacial and postglacial sediments are first described. Then, the compatibility of these data with our estimate of the modern abyssal circulation is assessed. For an easier interpretation of the results, the compatibility is examined separately for the two types of paleoceanographic observation; that is, the hypothesis of a consistency with the modern flow is tested first for $\delta^{18} \mathrm{O}_{\mathrm{b}}$ and then for $\delta^{13} \mathrm{C}_{\mathrm{b}}$.

\section{a. Compilation}

We have compiled measurements of benthic foraminiferal $\delta^{18} \mathrm{O}$ and $\delta^{13} \mathrm{C}$ for the Holocene and the Last

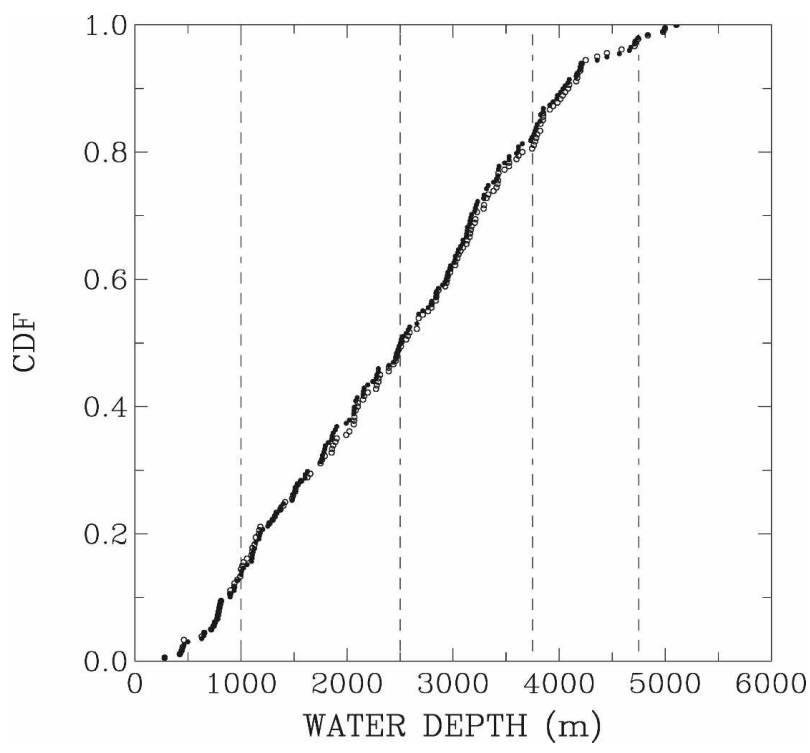

FIG. 10. Cumulative distribution function of the water depths of the sediment cores considered in our compilation of benthic foraminiferal data for the Holocene (solid circles) and LGM (open circles). The vertical dashed lines indicate the model vertical levels of 1000, 2500, 3750, and $4750 \mathrm{~m}$. Approximately $50 \%$ of the cores originate from water depths shallower than $2500 \mathrm{~m}$ and $80 \%$ of the cores originate from water depths shallower than $3750 \mathrm{~m}$.

Glacial Maximum, combining data from several syntheses (e.g., Sarnthein et al. 1994; Bickert and Mackensen 2003; Curry and Oppo 2005) as well as other sources (our compilation is available at http://www.ngdc.noaa. gov/). Our operational definitions of the Holocene and LGM are, respectively, the time intervals 0-3 kyr BP and 18-21 kyr BP. Our compilation includes 198 measurements of both $\delta^{18} \mathrm{O}_{\mathrm{b}}$ and $\delta^{13} \mathrm{C}_{\mathrm{b}}$ for the Holocene and 180 measurements of both $\delta^{18} \mathrm{O}_{\mathrm{b}}$ and $\delta^{13} \mathrm{C}_{\mathrm{b}}$ for the LGM (Fig. 3). These measurements were done exclusively on the benthic taxa Cibicidoides and Planulina. Both postglacial and glacial values are available at most of the core locations. These locations span the depth range $280-5105 \mathrm{~m}$, with $50 \%(80 \%)$ of the cores raised from depths shallower than $2500 \mathrm{~m}$ (3750 m) (Fig. 10).

The errors in our compiled $\delta^{18} \mathrm{O}_{\mathrm{b}}$ and $\delta^{13} \mathrm{C}_{\mathrm{b}}$ data come from various sources associated with core chronology, the motion postmortem of shells within the sedimentary column (bioturbation), the instruments (mass spectrometers), and the oceanic representativity of shell isotopic composition. For sediment cores with reliable chronology and high accumulation rates, we feel confident that the $\delta^{18} \mathrm{O}_{\mathrm{b}}$ and $\delta^{13} \mathrm{C}_{\mathrm{b}}$ values we have selected are representative of the two time intervals. For the other cores, we admit that some of our selected values may not be representative of these intervals. Errors associated with mass spectrometry can be signifi- 
cant, in particular for $\delta^{18} \mathrm{O}$. Zahn and Mix (1991) concluded that some of the observed $\delta^{18} \mathrm{O}_{\mathrm{b}}$ gradients for the glacial Atlantic might be an artifact of instrumental errors. An intercalibration study showed that measurements of the same standard sample on 20 mass spectrometers varied over a range of $0.27 \%$ for $\delta^{18} \mathrm{O}$ and $0.11 \%$ for $\delta^{13} \mathrm{C}$, with standard deviations of $0.07 \%$ and $0.03 \%$, respectively (Ostermann and Curry 2000). The oceanic representativity of shell isotopic composition $\left(\delta^{18} \mathrm{O}_{\mathrm{b}}\right.$ and $\left.\delta^{13} \mathrm{C}_{\mathrm{b}}\right)$ is discussed in appendix C. Here, spatially uniform uncertainties are assumed for both $\delta^{18} \mathrm{O}_{\mathrm{b}}$ and $\delta^{13} \mathrm{C}_{\mathrm{b}}$ (section $4 \mathrm{~d}$ ), although the accuracy of our compiled data is probably variable. For example, there may be a bias toward $\delta^{13} \mathrm{C}_{\mathrm{b}}$ values that are lower than the $\delta^{13} \mathrm{C}_{\mathrm{DIC}}$ of ambient bottom water in some regions of high productivity (Mackensen et al. 1993).

\section{b. Mapping}

An objective interpolation technique (GaussMarkov smoother) is used to estimate $\delta^{18} \mathrm{O}_{\mathrm{c}}$ and $\delta^{13} \mathrm{C}_{\text {DIC }}$ (and their errors) at the regularly spaced model grid points from the estimates of $\delta^{18} \mathrm{O}_{\mathrm{c}}$ and $\delta^{13} \mathrm{C}_{\mathrm{DIC}}$ (and their errors) at the irregularly spaced core locations (e.g., Wunsch 1996). Let $\mathbf{S}_{\mathrm{CC}}=\left\langle\mathbf{C} \mathbf{C}^{\mathrm{T}}\right\rangle$ be the second-moment matrix for $\delta^{18} \mathrm{O}_{\mathrm{c}}$ or $\delta^{13} \mathrm{C}_{\mathrm{DIC}}$ and $\mathbf{S}_{\mathrm{nn}}=$ $\left\langle\mathbf{n n}^{\mathrm{T}}\right\rangle$ the second-moment matrix for the $\delta^{18} \mathrm{O}_{\mathrm{c}}$ or $\delta^{13} \mathrm{C}_{\mathrm{DIC}}$ errors (noise). We assume

$$
\begin{aligned}
\left(\mathbf{S}_{\mathrm{CC}}\right)_{i j} & =s_{0}^{2} \exp \left[-\frac{\Delta_{H}\left(\mathbf{r}_{i}, \mathbf{r}_{j}\right)}{l_{H}}\right] \exp \left[-\frac{\Delta_{Z}\left(\mathbf{r}_{i}, \mathbf{r}_{j}\right)}{l_{Z}}\right], \\
\left(\mathbf{S}_{\mathrm{nn}}\right)_{i j} & =s_{i j}^{2} \delta_{i j} .
\end{aligned}
$$

Here, $\Delta_{H}\left(\mathbf{r}_{i}, \mathbf{r}_{j}\right)\left[\Delta_{Z}\left(\mathbf{r}_{i}, \mathbf{r}_{j}\right)\right]$ is the horizontal (vertical) distance between the positions $\mathbf{r}_{i}$ and $\mathbf{r}_{j}, l_{H}\left(l_{Z}\right)$ is a horizontal (vertical) correlation scale, $s_{0}^{2}$ is a variance estimate, and $s_{i i}^{2}$ is the $\delta^{18} \mathrm{O}_{\mathrm{c}}$ or $\delta^{13} \mathrm{C}_{\mathrm{DIC}}$ variance at the $i$ th core location. Equation (7) states that the covariance between $\delta^{18} \mathrm{O}_{\mathrm{c}}$ or $\delta^{13} \mathrm{C}_{\text {DIC }}$ at two locations drops by $e^{-1}$ as the horizontal (vertical) distance between the two locations increases by $l_{H}\left(l_{Z}\right)$. Equation (8) states that the $\delta^{18} \mathrm{O}_{\mathrm{c}}$ or $\delta^{13} \mathrm{C}_{\text {DIC }}$ errors are uncorrelated. The mapping implies that far from core locations the gridded $\delta^{18} \mathrm{O}_{\mathrm{c}}\left(\delta^{13} \mathrm{C}_{\text {DIC }}\right)$ tends to the average of the $\delta^{18} \mathrm{O}_{\mathrm{b}}$ $\left(\delta^{13} \mathrm{C}_{\mathrm{b}}\right)$ measurements with a standard deviation $s_{0}$.

Note the highly arbitrary character of (7)-(8). For example, other expressions for the spatial correlations may be equally valid; it is assumed that the horizontal or vertical correlation can be described by a single scale, and the errors in $\delta^{18} \mathrm{O}_{\mathrm{c}}$ or $\delta^{13} \mathrm{C}_{\text {DIC }}$ may be correlated. The only benefits of objective interpolation compared to earlier mapping (e.g., Curry and Oppo 2005) are probably that the assumptions involved are stated explicitly and are (in principle) testable (Bretherton et al. 1976). The sensitivity of our results to the values assumed for the mapping parameters $\left(s_{i i}, s_{0}, l_{H}, l_{Z}\right)$ is explored in sections 4 and 5 . For each combination of $\left(s_{i i}, s_{0}, l_{H}, l_{Z}\right)$, the mapping is checked a posteriori by comparing the mapped $\delta^{18} \mathrm{O}_{\mathrm{c}}\left(\delta^{13} \mathrm{C}_{\text {DIC }}\right)$ at core locations with the values of $\delta^{18} \mathrm{O}_{\mathrm{c}}\left(\delta^{13} \mathrm{C}_{\mathrm{DIC}}\right)$ estimated from the $\delta^{18} \mathrm{O}_{\mathrm{b}}\left(\delta^{13} \mathrm{C}_{\mathrm{b}}\right)$ measurements (not shown). For each combination, less than $5 \%$ of the mapped values differ from the estimated values by more than two standard deviations $\left(2 s_{i i}\right)$, suggesting that the smoothing is consistent with the foraminiferal database.

\section{c. Tracer transport equations}

Statements about the effects of the time-mean flow on the water properties $\delta^{18} \mathrm{O}_{\mathrm{c}}$ and $\delta^{13} \mathrm{C}_{\mathrm{DIC}}$ must be assumed to interpret the data of benthic foraminiferal $\delta^{18} \mathrm{O}$ and $\delta^{13} \mathrm{C}$ in terms of the circulation. Consider first $\delta^{18} \mathrm{O}_{\mathrm{c}}$. Data from the Little Bahama Bank suggest that $\delta^{18} \mathrm{O}_{\mathrm{c}}$ can be approximated as a linear function of water $\delta^{18} \mathrm{O}$ and temperature [Eq. (1)]. Thus, we write

$$
\mathbf{u} \cdot \nabla \delta^{18} \mathrm{O}_{\mathrm{c}}=a_{1} \mathbf{u} \cdot \boldsymbol{\nabla} \delta^{18} \mathrm{O}_{\mathrm{w}}-a_{2} \mathbf{u} \cdot \boldsymbol{\nabla} T,
$$

where $\left(a_{1}, a_{2}\right)$ are constants. Assuming that the effects of mixing and compression on $\left(\delta^{18} \mathrm{O}_{\mathrm{w}}, T\right)$ can be represented implicitly (i.e., in the equations residuals), the transport equation for $\delta^{18} \mathrm{O}_{\mathrm{c}}$ is expressed as

$$
\mathbf{u} \cdot \boldsymbol{\nabla} \delta^{18} \mathrm{O}_{\mathrm{c}}=\tilde{\epsilon}_{\mathrm{O}} .
$$

A tilde is used above the residual in the differential equation to distinguish from the residual in the corresponding difference equation.

Then consider $\delta^{13} \mathrm{C}_{\text {DIC }}$. The transport equations for dissolved inorganic ${ }^{12} \mathrm{C}$ and ${ }^{13} \mathrm{C}$ are

$$
\begin{aligned}
& \mathbf{u} \cdot \nabla^{12} \mathrm{C}={ }^{12} J+{ }^{12} \tilde{\boldsymbol{\epsilon}}, \\
& \mathbf{u} \cdot \nabla^{13} \mathrm{C}={ }^{13} J+{ }^{13} \tilde{\boldsymbol{\epsilon}},
\end{aligned}
$$

where ${ }^{12} J\left({ }^{13} J\right)$ is the rate of production of dissolved inorganic ${ }^{12} \mathrm{C}\left({ }^{13} \mathrm{C}\right)$ owing to the remineralization of organic carbon. The rate of production of each isotope is given by

$$
{ }^{n} J=\left(\frac{{ }^{n} \mathrm{C}}{\mathrm{C}}\right)_{\text {org }} J,
$$

where $\left({ }^{n} \mathrm{C} / \mathrm{C}\right)_{\text {org }}$ is the ratio in organic matter and $J$ is the rate of remineralization of (total) organic carbon. Because about $99 \%$ of natural carbon is in the form of ${ }^{12} \mathrm{C},{ }^{12} \mathrm{C} \approx{ }^{12} \mathrm{C}+{ }^{13} \mathrm{C}$ for both inorganic and organic carbon. Likewise, $\left({ }^{13} \mathrm{C} / \mathrm{C}\right)_{\mathrm{org}} \approx\left({ }^{13} \mathrm{C} /{ }^{12} \mathrm{C}\right)_{\mathrm{org}}$. Hence, Eqs. (11)-(12) can be combined to give a transport equation for $\delta^{13} \mathrm{C}_{\mathrm{DIC}}$ : 


$$
\mathbf{u} \cdot \boldsymbol{\nabla} \delta^{13} \mathrm{C}_{\mathrm{DIC}}=J_{*}\left(\delta^{13} \mathrm{C}_{\mathrm{org}}-\delta^{13} \mathrm{C}_{\mathrm{DIC}}\right)+\tilde{\epsilon}_{\mathrm{C}}
$$

Here $J_{*}=J / \mathrm{C}, \mathrm{C}$ is the concentration of total dissolved inorganic carbon in seawater, and $\delta^{13} \mathrm{C}_{\text {org }}$ is the $\delta^{13} \mathrm{C}$ of organic matter. The difference forms of (10) and (14) as well as the values assumed for $J_{*}$ and $\delta^{13} C_{\text {org }}$ are reported in appendix A.

\section{d. Consistency tests}

In this section, the estimated distributions of $\delta^{18} \mathrm{O}_{\mathrm{c}}$ or $\delta^{13} \mathrm{C}_{\text {DIC }}$ for the Holocene or LGM are combined with our estimate of the modern flow to determine the adjustments in these distributions that are necessary to bring them into consistency with this flow. A useful measure of the overall adjustment is based on the difference between the posterior and prior values of $\delta^{18} \mathrm{O}_{\mathrm{c}}$ or $\delta^{13} \mathrm{C}_{\mathrm{DIC}}$ given the prior error; that is,

$$
t_{\alpha}=P\left(\left|\frac{\tilde{x}_{i}-x_{o, i}}{\sqrt{\mathrm{C}_{o, i}}}\right|>\alpha\right) .
$$

Here, $P(\cdot)$ is the probability function, $x_{i}$ is the value of $\delta^{18} \mathrm{O}_{\mathrm{c}}$ or $\delta^{13} \mathrm{C}_{\mathrm{DIC}}$ at the grid point closest to the $i$ th core location, and $\alpha$ is a specified level (note that more than one core location may have the same grid point as the closest point, so the number of grid points considered in $t_{2}$ is less than 198 for the Holocene and less than 180 for the LGM). For example, the situation $t_{2}=0.10$ signifies that $10 \%$ of the $\delta^{18} \mathrm{O}_{\mathrm{c}}$ or $\delta^{13} \mathrm{C}_{\mathrm{DIC}}$ values at grid points closest to core locations need to be altered from their prior values by more than two standard deviations to be consistent with the modern flow. Clearly, a small (high) value of $t_{2}$ would suggest acceptance (rejection) of $\mathrm{HO}$ [if $\left(\tilde{x}_{i}-x_{o, i}\right) / \sqrt{C_{o, i}}$ is normally distributed under H0, the situation $t_{2}>0.05$ would imply that $\mathrm{H} 0$ can be rejected at the $5 \%$ significance level].

\section{1) Distributions of $\delta^{18} \mathrm{O}_{\mathrm{C}}$ FOR Holocene And LGM}

The prior state $\mathbf{x}_{o}$ includes the transport components $(U, V, W)$ of the modern flow and the $\delta^{18} \mathrm{O}_{\mathrm{c}}$ estimates obtained by objective mapping of $\delta^{18} \mathrm{O}_{\mathrm{b}}$ data for the Holocene or LGM. A very small uncertainty $\left(10^{-6} \mathrm{~Sv}\right)$ is assumed for the transport components so that the inversion is constrained to find small modifications to the modern flow estimate. The uncertainties in the $\delta^{18} \mathrm{O}_{\mathrm{c}}$ estimates are provided by the mapping. The uncertainty in the prior $\left(\mathbf{C}_{o}\right)$ is taken as diagonal. The only constraint being considered is the $\delta^{18} \mathrm{O}_{\mathrm{c}}$ transport Eq. (A.8). Thus, assumptions about the following parameters must be made to interpret oceanographically the

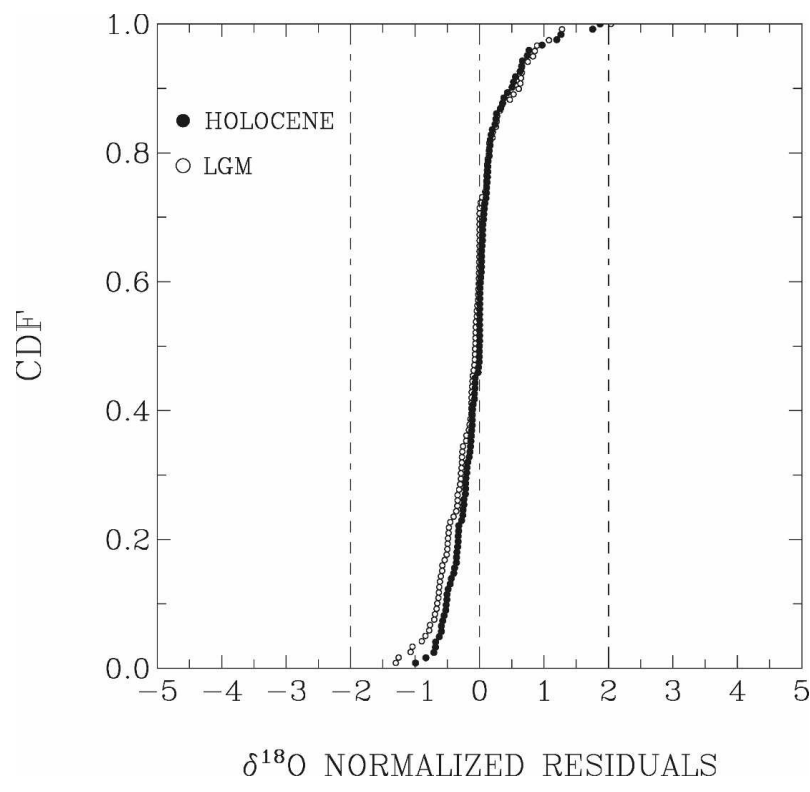

FIG. 11. Cumulative distribution function of the $\delta^{18} \mathrm{O}$ normalized residuals at the grid points closest to core locations. The inversion assumes $s_{i i}=s_{0}=0.2 \%, l_{H}=10^{6} \mathrm{~m}, l_{Z}=10^{3} \mathrm{~m}$, and $\left\langle\epsilon_{\mathrm{O}}^{2}\right\rangle^{1 / 2}=10^{3} \mathrm{~m}^{3} \mathrm{~s}^{-1} \%$.

$\delta^{18} \mathrm{O}_{\mathrm{b}}$ data: the standard deviation for the $\delta^{18} \mathrm{O}_{\mathrm{c}}$ estimates at core locations $\left(s_{i i}\right)$, the standard deviation for the $\delta^{18} \mathrm{O}_{\mathrm{c}}$ estimates far from these locations $\left(s_{0}\right)$, the correlation scales $\left(l_{H}, l_{Z}\right)$, and the standard deviation for (A.8) $\left(\left\langle\epsilon_{\mathrm{O}}^{2}\right\rangle^{1 / 2}\right)$. We report results obtained with different values of $\left(s_{i i}, s_{0}\right)$ and fixed values of $l_{H}=10^{6} \mathrm{~m}$, $l_{Z}=10^{3} \mathrm{~m}$, and $\left\langle\epsilon_{\mathrm{O}}^{2}\right\rangle^{1 / 2}=10^{3} \mathrm{~m}^{3} \mathrm{~s}^{-1} \%$. Note that $\mathrm{a}$ standard deviation $\left\langle\epsilon_{\mathrm{O}}^{2}\right\rangle^{1 / 2}=10^{3} \mathrm{~m}^{3} \mathrm{~s}^{-1} \%$ is probably optimistic. For example, in the abyssal interior, the transport is of $O(1) \mathrm{Sv}$ and the equilibrium calcite $\delta^{18} \mathrm{O}$ is of $O(1) \%$ (e.g., Zahn and Mix 1991), implying that the advective terms in (A.8) are generally of $O\left(10^{6}\right)$ $\mathrm{m}^{3} \mathrm{~s}^{-1} \%$. This latter value is larger than the assumed $\left\langle\epsilon_{\mathrm{O}}^{2}\right\rangle^{1 / 2}$ by three orders of magnitude. Use of a small error for (A.8), however, should more readily permit rejection of $\mathrm{H} 0$.

First consider results for $s_{i i}=0.2 \%$, which is the uncertainty adopted in earlier studies (e.g., LW95; Gebbie and Huybers 2006). To further facilitate comparison with these studies, we take $s_{0}=0.2 \%$, as they assume that the $\delta^{18} \mathrm{O}_{\mathrm{c}}$ estimates at grid locations have the same uncertainty as at core locations. We find that relatively small adjustments in the $\delta^{18} \mathrm{O}_{\mathrm{c}}$ distributions for the Holocene and LGM are necessary to bring these distributions into consistency with the modern circulation (Fig. 11). For the Holocene, none of the $\delta^{18} \mathrm{O}_{\mathrm{c}}$ values closest to core locations is adjusted by more than two standard deviations in absolute magnitude; that is, $t_{2}=0.00$. For the LGM, only one of such values occurs $\left(t_{2}=0.01\right)$. 


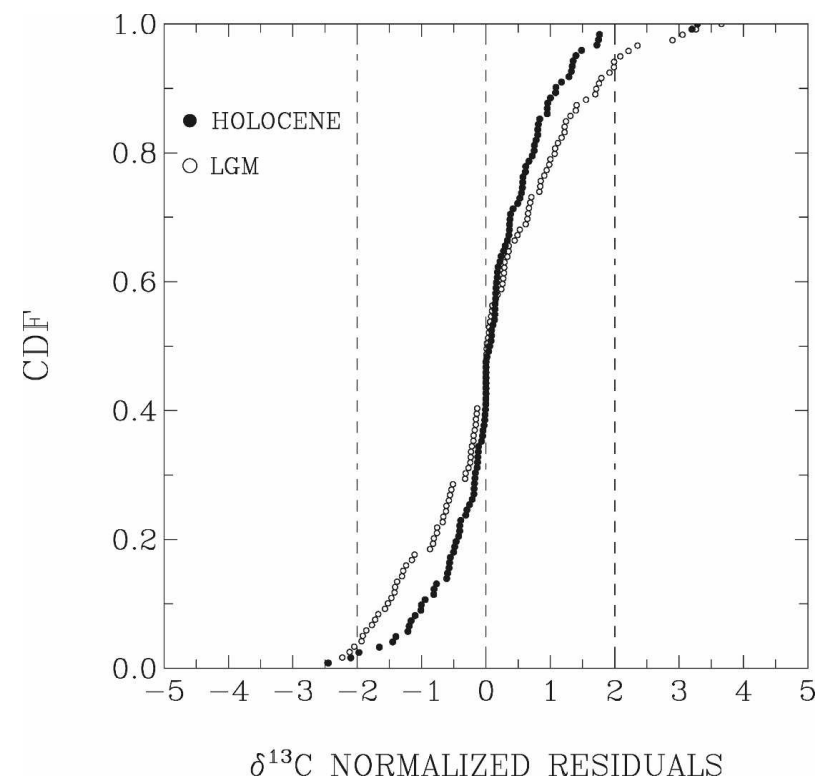

FIG. 12. Cumulative distribution function of the $\delta^{13} \mathrm{C}$ normalized residuals at the grid points closest to core locations. The inversion assumes $s_{i i}=s_{0}=0.2 \%, l_{H}=10^{6} \mathrm{~m}, l_{Z}=10^{3} \mathrm{~m}$, and $\left\langle\epsilon_{\mathrm{C}}^{2}\right\rangle^{1 / 2}=10^{3} \mathrm{~m}^{3} \mathrm{~s}^{-1} \%$.

Consider, then, the results for $s_{i i}=0.1 \%$ and $s_{0}=$ $0.2 \%$. It is unclear that an accuracy of $0.1 \%$ for $\delta^{18} \mathrm{O}_{\mathrm{c}}$ estimates at core locations is justified given, for example, the possible dispersion in our compiled $\delta^{18} \mathrm{O}_{\mathrm{b}}$ data associated with the use of different mass spectrometers. These results are nevertheless instructive, for they allow us to explore whether reducing the uncertainty in these estimates by a factor of 2 would suggest a larger inconsistency with the modern flow. In contrast, we find again small adjustments in the $\delta^{18} \mathrm{O}_{\mathrm{c}}$ distributions for the Holocene $\left(t_{2}=0.02\right)$ and LGM $\left(t_{2}=\right.$ 0.01) (not shown). Thus, even an optimistic assumption about the accuracy of the $\delta^{18} \mathrm{O}_{\mathrm{c}}$ estimates at core locations indicates that they are not incompatible with the modern circulation.

\section{2) Distributions of $\delta^{13} C_{\text {DiC }}$ FOr Holocene AND LGM}

The prior state $\mathbf{x}_{o}$ includes the transport components $(U, V, W)$ of the modern flow and the $\delta^{13} \mathrm{C}_{\mathrm{DIC}}$ estimates derived by objective mapping of $\delta^{13} \mathrm{C}_{\mathrm{b}}$ data for the Holocene or LGM. Again, a small uncertainty $\left(10^{-6} \mathrm{~Sv}\right)$ is assumed for the transport components, the uncertainties in the $\delta^{13} \mathrm{C}_{\mathrm{DIC}}$ estimates are provided by the mapping, and $\mathbf{C}_{o}$ is diagonal. The only constraint being considered is the $\delta^{13} \mathrm{C}_{\text {DIC }}$ transport Eq. (A.9). Thus, assumptions about the following parameters must be made to interpret the $\delta^{13} \mathrm{C}_{\mathrm{b}}$ data: the standard deviation for the $\delta^{13} \mathrm{C}_{\text {DIC }}$ estimates at core locations

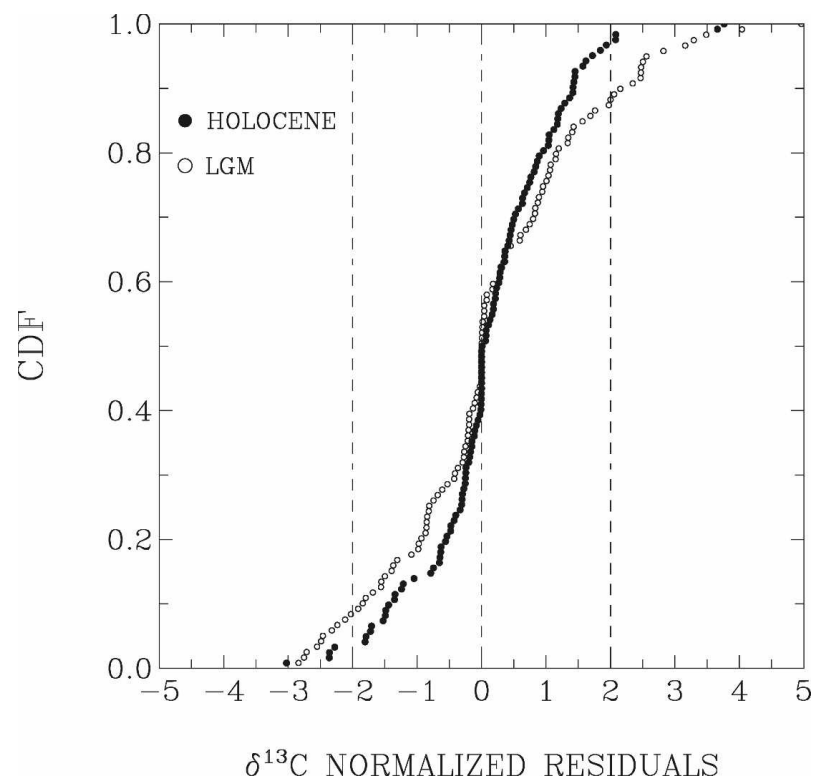

FIG. 13. Cumulative distribution function of the $\delta^{13} \mathrm{C}$ normalized residuals at the grid points closest to core locations. The inversion assumes $s_{i i}=0.1 \%$, $s_{0}=0.2 \%, l_{H}=10^{6} \mathrm{~m}, l_{Z}=10^{3} \mathrm{~m}$, and $\left\langle\epsilon_{\mathrm{C}}^{2}\right\rangle^{1 / 2}=10^{3} \mathrm{~m}^{3} \mathrm{~s}^{-1} \%$.

$\left(s_{i i}\right)$, the standard deviation for the $\delta^{13} \mathrm{C}_{\mathrm{DIC}}$ estimates far from these locations $\left(s_{0}\right)$, the correlation scales $\left(l_{H}\right.$, $l_{Z}$ ), and the standard deviation for (A.9) $\left(\left\langle\epsilon_{\mathrm{C}}^{2}\right\rangle^{1 / 2}\right)$. In this section, we illustrate results obtained with different values of $\left(s_{i i}, s_{0}\right)$ and fixed values of $l_{H}=10^{6} \mathrm{~m}, l_{Z}=10^{3}$ $\mathrm{m}$, and $\left\langle\epsilon_{\mathrm{C}}^{2}\right\rangle^{1 / 2}=10^{3} \mathrm{~m}^{3} \mathrm{~s}^{-1} \%$. Note that a standard deviation $\left\langle\epsilon_{\mathrm{C}}^{2}\right\rangle^{1 / 2}=10^{3} \mathrm{~m}^{3} \mathrm{~s}^{-1} \%$ is also optimistic; for example, this value is on the order of the source term in Eq. (A.9). Different values of $\left(s_{0}, l_{H}, l_{Z},\left\langle\epsilon_{\mathrm{C}}^{2}\right\rangle^{1 / 2}\right)$ are explored in section 5 .

First consider the results for $s_{i i}=0.2 \%$, which is the uncertainty assumed by LW95. To further facilitate comparison with this earlier study, we take $s_{0}=0.2 \%$. Albeit modest, the adjustments of the $\delta^{13} \mathrm{C}_{\text {DIC }}$ distributions to comply with the modern flow (Fig. 12) are larger than for the $\delta^{18} \mathrm{O}_{\mathrm{c}}$ distributions (Fig. 11). The number of $\delta^{13} \mathrm{C}_{\text {DIC }}$ values closest to core locations that are modified by more than two standard deviations amounts to 4 for the Holocene $\left(t_{2}=0.03\right)$ and 11 for the $\operatorname{LGM}\left(t_{2}=0.09\right)$.

Next, consider results for $s_{i i}=0.1 \%$ and $s_{0}=0.2 \%$. The $\delta^{13} \mathrm{C}_{\mathrm{DIC}}$ distributions are adjusted to a larger extent if a lower uncertainty in the $\delta^{13} \mathrm{C}_{\mathrm{DIC}}$ estimates at core locations is assumed (Fig. 13): the number of $\delta^{13} C_{\text {DIC }}$ values closest to core locations that are changed by more than two standard deviations is 8 for the Holocene $\left(t_{2}=0.07\right)$ and 25 for the LGM $\left(t_{2}=\right.$ $0.21)$. Thus, compatibility of the glacial $\delta^{13} \mathrm{C}_{\mathrm{b}}$ data with the modern circulation could be rejected with confi- 
dence (assuming normality). Interestingly, in both cases (Figs. 12-13), the $\delta^{13} \mathrm{C}_{\text {DIC }}$ distribution for the LGM must be altered to a larger degree than the $\delta^{13} \mathrm{C}_{\text {DIC }}$ distribution for the Holocene to reach consistency with the modern circulation.

\section{Discussion}

\section{a. Relation between $\delta^{18} \mathrm{O}_{c}$ and water density}

We examine whether the neglect of a possible relation between equilibrium calcite $\delta^{18} \mathrm{O}$ and water density (section 1) is not penalizing the capability of $\delta^{18} \mathrm{O}_{\mathrm{b}}$ data to provide information about the circulations for the Holocene and LGM. The provision of density estimates, if accurate enough, should provide strong constraints on the circulation via the thermal wind relations. The variation of $\rho$ with $\delta^{18} \mathrm{O}_{\mathrm{c}}$ and pressure $(p)$ in the Atlantic is estimated from measurements of the GEOSECS cruises (Bainbridge 1981; Ostlund et al. 1987). The equilibrium calcite $\delta^{18} \mathrm{O}$ is estimated from $\left(\delta^{18} \mathrm{O}_{\mathrm{w}}, T\right)$ using the regression to data from the Little Bahama Bank [Eq. (1)], whereas $\rho$ is computed from $(T, S, p)$ using EOS80. A multiple regression to the GEOSECS data yields (Fig. 14)

$$
\begin{aligned}
\rho= & 1025.89+0.82 \delta^{18} \mathrm{O}_{\mathrm{c}}+0.0044 p \\
& (R>0.99, n=167),
\end{aligned}
$$

where $\rho\left(\mathrm{kg} \mathrm{m}^{-3}\right), \delta^{18} \mathrm{O}_{\mathrm{c}}(\%)$, and $p(\mathrm{dbar})$. This equation is used to estimate $\rho$ at core locations for the Holocene and LGM from the core $\delta^{18} \mathrm{O}_{\mathrm{b}}$ data and water depths, assuming that $p$ (dbar) is numerically equal to $z$ in meters. Note that for the LGM, the data could be corrected for the changes in ocean mean $\delta^{18} \mathrm{O}_{\mathrm{w}}$ (Schrag et al. 2002) and global sea level over the deglaciation (Clark and Mix 2002). These corrections should have no influence on the results, however, as only density differences are dynamically relevant [Eqs. (A.2)(A.3)]. The uncertainty in the paleodensities $\left(s_{\rho}\right)$ are estimated by propagating the errors in $\delta^{18} \mathrm{O}_{\mathrm{c}}\left(s_{\delta}\right)$ and $p\left(s_{p}\right)$, assuming that these errors are uncorrelated:

$$
s_{\rho}=\sqrt{\left(0.82 s_{\delta}\right)^{2}+\left(0.0044 s_{p}\right)^{2}} .
$$

Note that $s_{\rho}$ should account, for example, for the errors in core chronology, the offset between $\delta^{18} \mathrm{O}_{\mathrm{b}}$ and $\delta^{18} \mathrm{O}_{\mathrm{c}}$, and the uncertainty in core paleodepth. For example, $s_{\delta}$ $=0.2 \% \mathrm{o}(0.1 \%)$ and $s_{p}=10 \mathrm{dbar}$ translate into $s_{\rho}=0.2$ $\mathrm{kg} \mathrm{m}^{-3}\left(0.1 \mathrm{~kg} \mathrm{~m}^{-3}\right)$, which are error estimates reported in earlier work (Hirschi and Lynch-Stieglitz 2006).

We thus consider results from two inversions with a different error for the paleodensity estimates at core locations $\left(s_{i i}=s_{\rho}\right): s_{i i}=0.2 \mathrm{~kg} \mathrm{~m}^{-3}$ and $s_{i i}=0.1 \mathrm{~kg} \mathrm{~m}^{-3}$.

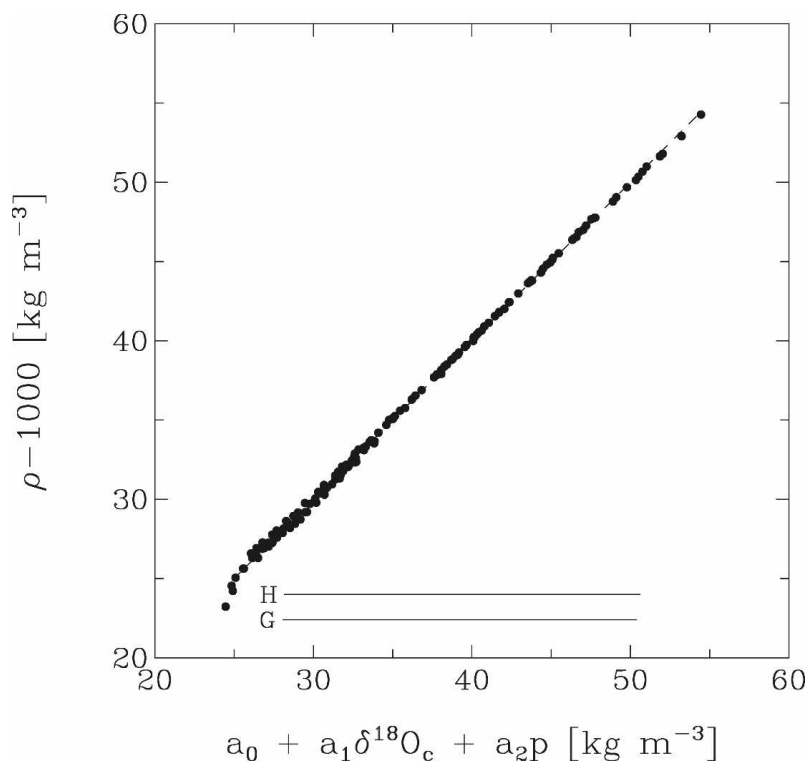

FIG. 14. Anomaly of in situ density vs a linear combination of equilibrium calcite $\delta^{18} \mathrm{O}$ and pressure for the Atlantic (data from Bainbridge 1981; Ostlund et al. 1987). In situ density is computed from in situ temperature $(T)$, salinity, and pressure using EOS80. The equilibrium calcite $\delta^{18} \mathrm{O}$ is computed from water $\delta^{18} \mathrm{O}$ and $T$ using the multiple regression for the Little Bahama Bank (data from Lynch-Stieglitz et al. 1999): $\delta^{18} \mathrm{O}_{\mathrm{c}}=(3.35-0.27)+$ $0.97 \delta^{18} \mathrm{O}_{\mathrm{w}}-0.21 T(R=0.98, n=91)$. The term $0.27 \%$ accounts for the different standards used for $\delta^{18} \mathrm{O}_{\mathrm{c}}$ and $\delta^{18} \mathrm{O}_{\mathrm{w}}$ (Zahn and Mix 1991). Only values between $46^{\circ} \mathrm{S}$ and $66^{\circ} \mathrm{N}$ are shown (for station locations see Fig. 3). The values of the coefficients $a_{0}=$ $1025.89 \mathrm{~kg} \mathrm{~m}^{-3}, a_{1}=0.82 \mathrm{~kg} \mathrm{~m}^{-3} \%{ }^{-1}$, and $a_{2}=0.0044 \mathrm{~kg} \mathrm{~m}^{-3}$ $\mathrm{dbar}^{-1}$ are obtained by multiple regression. The dashed line is the least squares fit $(r>0.99, n=167)$. The horizontal bars show the range of the combination $a_{0}+a_{1} \delta^{18} \mathrm{O}_{\mathrm{c}}+a_{2} p$ for the Holocene $(\mathrm{H})$ and the LGM (G) after accounting for (i) a change of $1 \%$ in ocean mean $\delta^{18} \mathrm{O}_{\mathrm{w}}$ (Schrag et al. 2002) and (ii) a change of $128 \mathrm{~m}$ in eustatic sea level during the deglaciation (Clark and Mix 2002).

Each inversion assumes $s_{0}=1.0 \mathrm{~kg} \mathrm{~m}^{-3}, l_{H}=10^{6} \mathrm{~m}, l_{Z}$ $=10^{3} \mathrm{~m}$, and the thermal wind relations (A.2)-(A.3) as dynamical constraints with $\left\langle\epsilon_{\mathrm{v}}^{2}\right\rangle^{1 / 2}=\left\langle\epsilon_{\mathrm{u}}^{2}\right\rangle^{1 / 2}=10^{2} \mathrm{~m}^{3} \mathrm{~s}^{-1}$. For the two values of $s_{i i}$, fewer than $5 \%$ of the mapped densities at core locations differ from the densities estimated from $\left(\delta^{18} \mathrm{O}_{\mathrm{b}}, \mathrm{z}\right)$ by more than $2 s_{i i}$ for both the Holocene and LGM. The relatively small standard deviation for (A.2)-(A.3) is on the order of the error assumed in earlier work to give $\delta^{18} \mathrm{O}_{\mathrm{b}}$ data the best chance of constraining the circulation (Gebbie and Huybers 2006). We find that for both values of $s_{i i}$, relatively modest adjustments in the paleodensity estimates are necessary to bring these estimates into dynamical consistency with the modern circulation $\left(t_{2} \leq 0.05\right.$ for both Holocene and LGM). Thus, the consideration of a possible relationship between equilibrium calcite $\delta^{18} \mathrm{O}$ and water density still indicates that the benthic $\delta^{18} \mathrm{O}$ 
data are not incompatible with the modern flow given the uncertainties.

\section{b. Sensitivity to tracer source}

We examine whether the conservative character of $\delta^{18} \mathrm{O}_{\mathrm{c}}$ affects the capability of this tracer to provide information about the circulation compared to $\delta^{13} \mathrm{C}_{\mathrm{DIC}}$. To illustrate this possibility, consider the generic transport equation

$$
\mathbf{u} \cdot \nabla C=J+\tilde{\epsilon}
$$

The adjustment experienced by the tracer distribution to comply with a flow can be given a closed form in the limits where $\mathbf{u}$ is known perfectly and the constraint $\mathbf{u} \cdot \nabla C=J$ is exact. This constraint then leads to a discrete linear system of the form $\mathbf{A x}=\mathbf{b}$, where the state $\mathbf{x}$ includes only the tracer distribution and $\mathbf{b}=\mathbf{0}$ $(\neq \mathbf{0})$ if the tracer is conservative (nonconservative). It can be represented in the cost function by a term proportional to a vector $\boldsymbol{\mu}$ of Lagrange multipliers (e.g., Wunsch 1996):

$$
I=\left(\mathbf{x}-\mathbf{x}_{o}\right)^{\mathrm{T}} \mathbf{C}_{o}^{-1}\left(\mathbf{x}-\mathbf{x}_{o}\right)-2 \boldsymbol{\mu}^{\mathrm{T}}(\mathbf{A} \mathbf{x}-\mathbf{b}) .
$$

The tracer distribution that satisfies both the prior state $\mathbf{x}_{o}$ given its uncertainty $\mathbf{C}_{o}$ and the exact system $\mathbf{A x}=\mathbf{b}$ is

$$
\tilde{\mathbf{x}}=\mathbf{x}_{o}+\mathbf{C}_{o} \mathbf{A}^{\mathrm{T}}\left(\mathbf{A} \mathbf{C}_{o} \mathbf{A}^{\mathrm{T}}\right)^{-1}\left(\mathbf{b}-\mathbf{A} \mathbf{x}_{o}\right) .
$$

Thus, unless the prior state complies exactly with the constraint $\left(\mathbf{A} \mathbf{x}_{o}=\mathbf{b}\right)$, the tracer distribution is adjusted by an amount $\tilde{\mathbf{x}}-\mathbf{x}_{o}$. In the presence of a source, the tracer adjustment $\tilde{\mathbf{x}}-\mathbf{x}_{o}$ is modified by the vector addition of $+\mathbf{C}_{o} \mathbf{A}^{\mathrm{T}}\left(\mathbf{A} \mathbf{C}_{o} \mathbf{A}^{\mathrm{T}}\right)^{-1} \mathbf{b}$, where $\mathbf{C}_{o} \mathbf{A}^{\mathrm{T}}\left(\mathbf{A} \mathbf{C}_{o} \mathbf{A}^{\mathrm{T}}\right)^{-1}$ plays the role of a Moore-Penrose inverse. The adjustment can be altered both qualitatively and quantitatively, which echoes the heuristic considerations in section 1.

We explore the role of the source term (remineralization) in the inversion showing the largest inconsistency of the glacial $\delta^{13} \mathrm{C}_{\text {DIC }}$ estimates with the modern flow (Fig. 13). The inversion is repeated with the same values of $\left(s_{i i}, s_{0}, l_{H}, l_{Z},\left\langle\epsilon_{\mathrm{C}}^{2}\right\rangle^{1 / 2}\right)$ but with $J=0$. We find that the number of $\delta^{13} \mathrm{C}_{\mathrm{DIC}}$ values closest to core locations that are altered by more than $2 s_{i i}$ amounts to 20 (instead of 25 when remineralization is included); that is, $t_{2}=0.17$ (instead of $t_{2}=0.21$ ). Hence, the neglect of the source in the $\delta^{13} \mathrm{C}_{\text {DIC }}$ transport equation reduces only slightly the apparent incompatibility of the $\delta^{13} \mathrm{C}_{\mathrm{b}}$ data with the modern flow. The different capabilities of $\delta^{18} \mathrm{O}_{\mathrm{b}}$ and $\delta^{13} \mathrm{C}_{\mathrm{b}}$ data to test $\mathrm{H} 0$ seem unrelated to the remineralization effect on $\delta^{13} \mathrm{C}_{\mathrm{DIC}}$ but to the different property distributions inferred from these data. Note that the modest influence of remineralization could have been anticipated from the quasi-conservative character of $\delta^{13} \mathrm{C}_{\text {DIC }}$ in the modern Atlantic [i.e., $J_{*}^{-1}=$ $O\left(10^{4}\right) \mathrm{yr}$, which is much larger than the time scales of the abyssal motions].

\section{c. Sensitivity to mapping assumptions}

We conduct inversions of glacial $\delta^{13} \mathrm{C}_{\mathrm{DIC}}$ estimates obtained from more conservative assumptions about the mapping parameters $\left(s_{0}, l_{H}, l_{Z}\right)$. Unless stipulated otherwise, the values of $\left(s_{i i}, s_{0}, l_{H}, l_{Z},\left\langle\epsilon_{\mathrm{C}}^{2}\right\rangle^{1 / 2}\right)$ are those of the inversion showing the largest incompatibility of these estimates with the modern flow (Fig. 13). Consider two inversions with $s_{0}=0.3 \%$ and $0.4 \%$. For $s_{0}=$ $0.3 \%$ o $\left(0.4 \%\right.$ o only nine (three) of the $\delta^{13} \mathrm{C}_{\text {DIC }}$ estimates at grid points closest to core locations are modified by more than two standard deviations; that is, $t_{2}=0.08\left(t_{2}=\right.$ 0.03). Consider then two other inversions, one with $l_{H}=0.5 \times 10^{6} \mathrm{~m}$ and another with $l_{Z}=500 \mathrm{~m}$. In the first inversion, the number of $\delta^{13} \mathrm{C}_{\mathrm{DIC}}$ estimates closest to core locations that are altered by more than two standard deviations amounts to $20\left(t_{2}=0.17\right)$. In the second inversion, this number equals $17\left(t_{2}=0.14\right)$.

Thus, the adjustment of the glacial $\delta^{13} \mathrm{C}_{\mathrm{DIC}}$ distribution to comply with the modern flow is particularly sensitive to the standard deviation assumed for $\delta^{13} \mathrm{C}_{\mathrm{DIC}}$ far from core locations. The sensitivity to the correlation scales is less pronounced. The consistency of glacial $\delta^{13} \mathrm{C}_{\mathrm{b}}$ data with the modern flow would still be rejected at the 5\% significance level in all cases, except for $s_{0} \geq$ $0.4 \%$. Rejection at this level, however, would still rely on the assumptions that (i) a standard deviation $\left\langle\epsilon_{\mathrm{C}}^{2}\right\rangle^{1 / 2}=$ $10^{3} \mathrm{~m}^{3} \mathrm{~s}^{-1} \%$ is an appropriate error for the $\delta^{13} \mathrm{C}_{\text {DIC }}$ transport equation and (ii) the $\delta^{13} \mathrm{C}_{\mathrm{DIC}}$ normalized residuals are normally distributed under $\mathrm{H} 0$.

\section{d. Sensitivity to model error}

We now perform inversions of the glacial $\delta^{13} C_{\text {DIC }}$ estimates by making more conservative assumptions about the uncertainty in the $\delta^{13} \mathrm{C}_{\mathrm{DIC}}$ transport equation $\left(\left\langle\epsilon_{\mathrm{C}}^{2}\right\rangle^{1 / 2}\right)$. Again, the values of $\left(s_{i i}, s_{0}, l_{H}, l_{Z}\right)$ are those of the inversion leading to the largest apparent inconsistency of these estimates with the modern flow (Fig. 13). Values of $\left\langle\epsilon_{\mathrm{C}}^{2}\right\rangle^{1 / 2}$ ranging from $10^{3}$ to $10^{6} \mathrm{~m}^{3} \mathrm{~s}^{-1} \%$ are considered (Fig. 15). The former value is on the order of magnitude of the source term in Eq. (A.9), whereas the latter value is on the order of the advective terms in this equation. We find that the adjustment of the $\delta^{13} \mathrm{C}_{\mathrm{DIC}}$ distribution becomes minor (i.e., $t_{2}<0.05$ ) when the order of magnitude of $\left\langle\epsilon_{\mathrm{C}}^{2}\right\rangle^{1 / 2}$ exceeds $10^{3}$ $\mathrm{m}^{3} \mathrm{~s}^{-1} \%$ (solid circles in Fig. 15).

The decrease in the $\delta^{13} \mathrm{C}_{\text {DIC }}$ adjustment with increasing $\left\langle\epsilon_{\mathrm{C}}^{2}\right\rangle^{1 / 2}$ (Fig. 15) can be easily rationalized. Because 


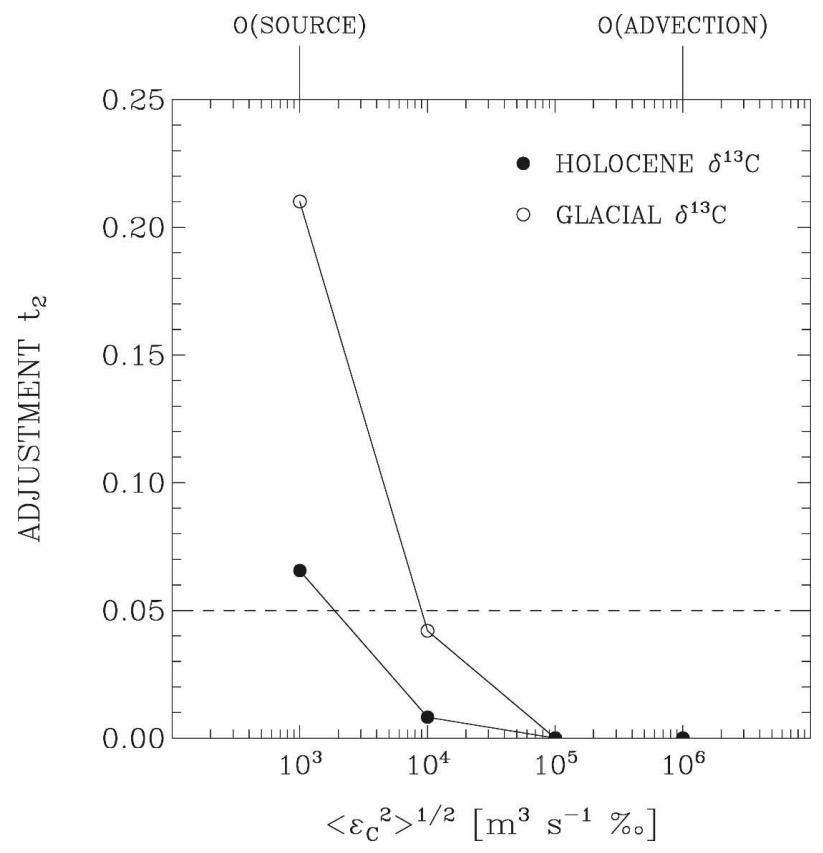

FIG. 15. Adjustment of the $\delta^{13} \mathrm{C}_{\text {DIC }}$ distributions for the Holocene (solid circles) and the LGM (open circles) as a function of the std dev assumed for the $\delta^{13} \mathrm{C}_{\mathrm{DIC}}$ transport equation. The order of magnitude of the source term (advection terms) in this equation is $10^{3} \mathrm{~m}^{-3} \mathrm{~s}^{-1} \%$ o $\left(10^{6} \mathrm{~m}^{-3} \mathrm{~s}^{-1} \%\right.$ o).

a large weight is put on the prior values of the transport components, the constraint (A.9) is approximately linear. Thus, to a good approximation, the cost has the general form

$$
I=\left(\mathbf{x}-\mathbf{x}_{o}\right)^{\mathrm{T}} \mathbf{C}_{o}^{-1}\left(\mathbf{x}-\mathbf{x}_{o}\right)+(\mathbf{A} \mathbf{x}-\mathbf{b})^{\mathrm{T}} \mathbf{C}_{\mathrm{A}}^{-1}(\mathbf{A} \mathbf{x}-\mathbf{b}) .
$$

Minimizing $I$ with respect to $\mathbf{x}$ yields the normal equations

$$
\left(\mathbf{C}_{o}^{-1}+\mathbf{A}^{\mathrm{T}} \mathbf{C}_{\mathrm{A}}^{-1} \mathbf{A}\right) \tilde{\mathbf{x}}=\mathbf{C}_{o}^{-1} \mathbf{x}_{o}+\mathbf{A}^{\mathrm{T}} \mathbf{C}_{\mathrm{A}}^{-1} \mathbf{b} .
$$

As the diagonal elements of $\mathbf{C}_{\mathrm{A}}$ become very large $\left(\mathbf{C}_{\mathrm{A}}^{-1} \rightarrow \mathbf{0}\right)$, the posterior state is approximately the prior state $\left(\tilde{\mathbf{x}} \approx \mathbf{x}_{o}\right)$. Thus, as the $\delta^{13} \mathrm{C}_{\text {DIC }}$ transport equation is deemed to be less accurate, the adjustment of the $\delta^{13} \mathrm{C}_{\mathrm{DIC}}$ distributions to satisfy a given flow is reduced.

\section{e. Locations of large inconsistency}

We identify the locations where the glacial $\delta^{13} \mathrm{C}_{\mathrm{DIC}}$ needs to be adjusted by more than $2 s_{i i}$ (in absolute magnitude) to reach consistency with the modern circulation. These critical locations are shown for the inversion indicating the largest incompatibility of glacial $\delta^{13} \mathrm{C}_{\mathrm{DIC}}$ estimates with the modern flow (Fig. 13). Re-

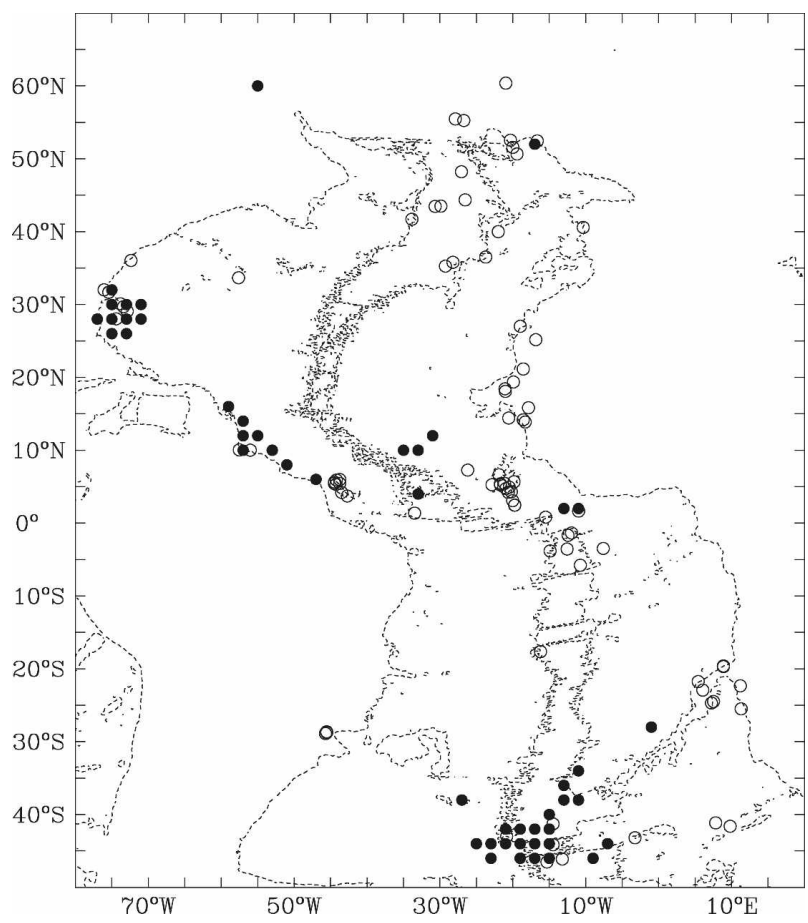

FIG. 16. Locations where the glacial $\delta^{13} \mathrm{C}_{\text {DIC }}$ estimates at depth $3750 \mathrm{~m}$ are increased by more than two std dev to be consistent with the modern circulation (solid circles) and locations of the sediment cores raised from water depths $>2500 \mathrm{~m}$ (open circles). The dashed line is the isobath of $3750 \mathrm{~m}$.

jection of $\mathrm{H} 0$ is due to the availability of $\delta^{13} \mathrm{C}_{\mathrm{b}}$ data at these locations, combined with several assumptions, such as that the reconstructed $\delta^{13} \mathrm{C}_{\mathrm{DIC}}$ have an uncertainty of $0.1 \%$. Whether this value is a valid uncertainty estimate at these specific locations is unclear, given the difficulty to constrain the errors in core chronology and the scarcity of calibration studies (appendix C). Thus, a better understanding of the errors in core chronology and further $\delta^{13} \mathrm{C}$ measurements in water and sediment at these locations should be useful. Note, on the other hand, that other locations may well exist that are not identified below but for which the provision of $\delta^{13} \mathrm{C}_{\text {DIC }}$ estimates might lead to even a stronger rejection of $\mathrm{H} 0$.

First consider the locations where the glacial $\delta^{13} \mathrm{C}_{\mathrm{DIC}}$ estimate must be increased by more than two standard deviations to reach consistency with the modern flow. The number of such locations amounts to 40,39, 49, and 22 at the depths of $1000,2500,3750$, and $4750 \mathrm{~m}$, respectively. At $3750 \mathrm{~m}$, these locations occur namely along the western boundary in the Northern Hemisphere and on the MAR in the Southern Hemisphere (solid circles in Fig. 16).

Next, consider the locations where the glacial $\delta^{13} \mathrm{C}_{\text {DIC }}$ must be decreased by more than two standard deviations to be compatible with the modern flow. The 


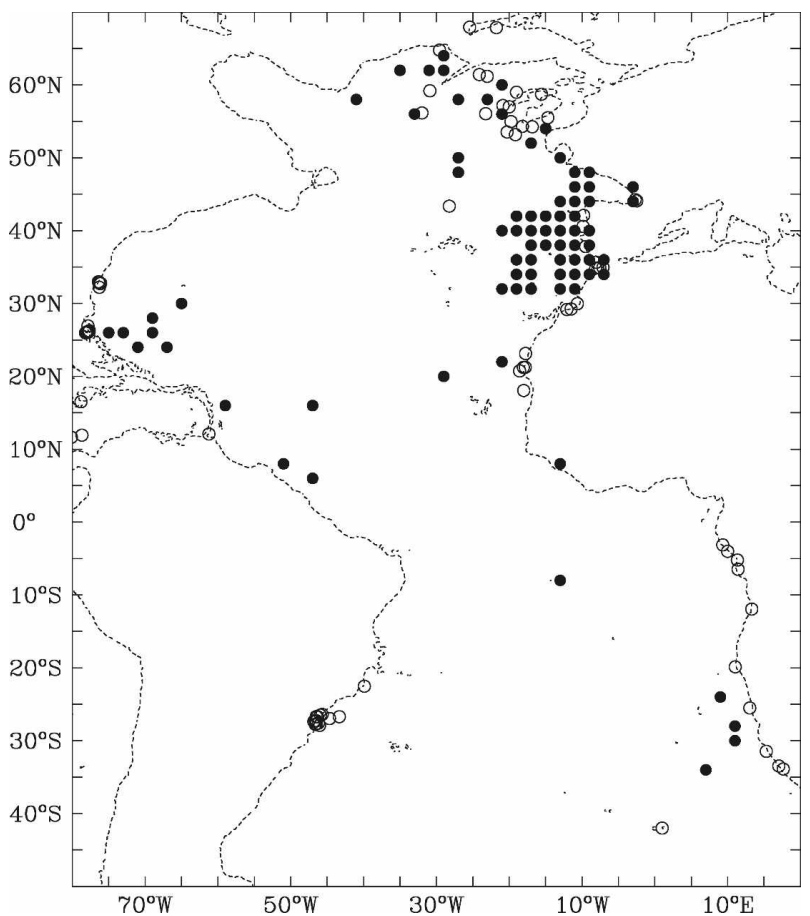

FIG. 17. Locations where the glacial $\delta^{13} \mathrm{C}_{\text {DIC }}$ estimates at depth $1000 \mathrm{~m}$ are decreased by more than two std dev to be consistent with the modern circulation (solid circles) and locations of the sediment cores raised from water depths $<2500 \mathrm{~m}$ (open circles). The dashed line is the isobath of $1000 \mathrm{~m}$.

number of such locations amounts to $77,29,13$, and 0 at the depths of $1000,2500,3750$, and $4750 \mathrm{~m}$, respectively. Thus, in contrast to the negative $\delta^{13} \mathrm{C}_{\text {DIC }}$ adjustments, the positive $\delta^{13} \mathrm{C}_{\text {DIC }}$ adjustments exhibit a consistent vertical pattern. At $1000 \mathrm{~m}$, the critical locations are primarily in the eastern North Atlantic (solid circles in Fig. 17), which is also where the bulk of the shallow cores are located (open circles in Fig. 17).

The adjustment of the glacial $\delta^{13} \mathrm{C}_{\text {DIC }}$ distribution to comply with the modern flow exhibits a pattern (maximum number of positive adjustments at $3750 \mathrm{~m}$ and maximum number of negative adjustments at $1000 \mathrm{~m}$ ) reminiscent of the contention that the large $\delta^{13} \mathrm{C}_{\mathrm{b}}$ differences between shallow and deep cores in the glacial Atlantic require a water mass distribution different from the modern (e.g., Curry and Oppo 2005). The pattern of the adjustment cannot easily be explained by a different remineralization rate at the LGM, as this would rather lead to positive or negative adjustments at all depths. Note also the large number of negative adjustments near the Strait of Gibraltar (Fig. 17). It may be tempting to ascribe this result to a greater influence of MOW during the LGM (the modern MOW is characterized by relatively high $\delta^{13} \mathrm{C}_{\mathrm{DIC}}$; e.g., Duplessy 1972). Whereas an earlier investigation concluded for an increase influence of MOW in the eastern North Atlantic during the LGM (Zahn et al. 1987), a more recent study postulated that the proportion of MOW reaching the upper Portuguese margin at the time was reduced (Zahn et al. 1997).

\section{f. Comparison to earlier studies}

We compare our major findings with earlier applications of inverse methods to paleoceanography. Our result that most of the $\delta^{18} \mathrm{O}_{\mathrm{b}}$ and $\delta^{13} \mathrm{C}_{\mathrm{b}}$ data for the LGM (more than $\sim 80 \%$ ) can be brought into consistency with the modern circulation in the Atlantic resonates with earlier conclusions (LW95; Gebbie and Huybers 2006). On the other hand, our work extends these two studies in significant respects. First consider LW95, who relied on 94 measurements of $\delta^{18} \mathrm{O}_{\mathrm{b}}$ and 115 measurements of $\delta^{13} C_{b}$ for the LGM (their Table 2). Our updated compilation for the LGM includes $91 \%$ more data of $\delta^{18} \mathrm{O}_{\mathrm{b}}$ and $57 \%$ more data of $\delta^{13} \mathrm{C}_{\text {DIC }}$, with a large addition of data from the western Atlantic. We find that the $\delta^{13} \mathrm{C}_{\mathrm{b}}$ data are generally less consistent with the modern circulation than the $\delta^{18} \mathrm{O}_{\mathrm{b}}$ data. This result could not have been obtained by LW95, as they inverted simultaneously both types of paleoceanographic observation. We find that the $\delta^{13} \mathrm{C}_{\mathrm{b}}$ data for the Holocene are generally more compatible with the modern circulation than the $\delta^{13} \mathrm{C}_{\mathrm{b}}$ data for the LGM. We determine two assumptions (besides normality) that lead one to reject with confidence the consistency of the glacial $\delta^{13} \mathrm{C}_{\mathrm{b}}$ data with the modern flow: the glacial $\delta^{13} \mathrm{C}_{\text {DIC }}$ estimates have an uncertainty of $\pm 0.1 \%$ and the $\delta^{13} \mathrm{C}_{\mathrm{DIC}}$ balance in the glacial deep Atlantic was dominated by a balance between the effects of advection and remineralization. Finally, we identify geographic locations where additional $\delta^{13} \mathrm{C}$ measurements would improve our understanding of the uncertainties in the glacial $\delta^{13} \mathrm{C}_{\mathrm{DIC}}$ estimates and hence our capability to test $\mathrm{H} 0$.

Next, consider Gebbie and Huybers (2006). Using $\delta^{18} \mathrm{O}_{\mathrm{b}}$ data from the western and eastern margins of the South Atlantic (depth range 200-2000 m), these authors concluded that it appears necessary to better determine the relationship between $\delta^{18} \mathrm{O}_{c}$ and water density to put firm constraints on meridional transport during the LGM (note that they used a different approach than ours to constrain in situ densities from $\delta^{18} \mathrm{O}_{\mathrm{b}}$ and core depth). Here, we show that paleodensity estimates for the abyssal (North and South) Atlantic derived from a regression of $\rho$ against $\left(\delta^{18} \mathrm{O}_{c}, p\right)$ based on modern observations are not dynamically incompatible with the three-dimensional, modern circulation.

Huybers et al. (2007) examined the extent to which idealized paleoceanographic data (e.g., $\delta^{13} \mathrm{C}_{\mathrm{DIC}}$ esti- 
mates) constrain the integrated meridional transport of volume in a rectangular, single-hemisphere abyssal ba$\sin$. They concluded that ruling out factor-of- 2 changes in the transport would require an accuracy $( \pm 0.01 \%$ for $\delta^{13} \mathrm{C}_{\text {DIC }}$ ) that is one order of magnitude better than is presently available. Our results suggest that an uncertainty in the $\delta^{13} C_{\text {DIC }}$ estimates on the order of $\pm 0.1 \%$ would actually suffice to reject at the $5 \%$ level the compatibility of the glacial $\delta^{13} \mathrm{C}_{\mathrm{b}}$ data with the threedimensional flow in the modern Atlantic, assuming normality and an advection-remineralization balance for $\delta^{13} \mathrm{C}_{\mathrm{DIC}}$.

\section{Summary and outlook}

We summarize our major results. First, the benthic $\delta^{13} \mathrm{C}$ data appear to provide more information about the abyssal circulation in the glacial Atlantic than do the benthic $\delta^{18} \mathrm{O}$ data. Second, the $\delta^{13} \mathrm{C}_{\mathrm{b}}$ data for the Holocene ( $\sim 0-3 \mathrm{kyr} \mathrm{BP})$ exhibit a better consistency with the modern circulation than the $\delta^{13} \mathrm{C}_{\mathrm{b}}$ data for the LGM ( 18-21 kyr BP). Finally, the $\delta^{13} \mathrm{C}_{\mathrm{b}}$ data for the LGM seem to be incompatible with the modern flow (i.e., $\mathrm{H} 0$ could be rejected at the 5\% significance level) only after two assumptions are made (besides normality): the $\delta^{13} \mathrm{C}_{\mathrm{DIC}}$ estimates derived from these data have an uncertainty of $\pm 0.1 \%$, and $\delta^{13} \mathrm{C}_{\mathrm{DIC}}$ in the glacial deep Atlantic was dominated by a balance between the advection by the mean flow and the effect of remineralization of organic carbon (e.g., mixing processes should have had a negligible influence). Note that the uncertainty in the $\delta^{13} \mathrm{C}_{\text {DIC }}$ estimates should account for the errors in both sediment core chronology and oceanic representativity of $\delta^{13} \mathrm{C}_{\mathrm{b}}$ measurements. Importantly, it is the statistical dispersion of the difference between $\delta^{13} \mathrm{C}_{\mathrm{b}}$ and $\delta^{13} \mathrm{C}_{\mathrm{DIC}}$ that is relevant for the interpretation of $\delta^{13} \mathrm{C}_{\mathrm{b}}$ data in our analysis-not the difference itself. Whereas the errors arising from core chronology are not readily quantifiable, the dispersion for $\delta^{13} \mathrm{C}_{\mathrm{b}}$ measurements on the genus Cibicidoides appears to be less than $\pm 0.1 \%$ on average (appendix $C$ ).

Major limitations of this work are clarified to identify possible perspectives. First, steady state has been assumed; that is, the premise has been adopted that paleoceanographic data pertaining to a $\sim 3$-kyr time interval can be treated as though they represented an unchanged system. The assumption is forced by data scarcity and cannot be rigorously defended. Second, sediment data have been combined with only one particular estimate of the modern circulation. A more complete analysis should probably consider a range of circulation estimates, because such estimates can ex- hibit important differences-in particular for the abyssal interior (appendix B). Thus, circulation estimates may well exist that would reveal a lower or even larger incompatibility of sediment data with the modern flow. Third, a higher vertical resolution should allow one to better represent some of the vertical gradients that are present in the $\delta^{18} \mathrm{O}_{\mathrm{b}}$ and $\delta^{13} \mathrm{C}_{\mathrm{b}}$ datasets, in particular in the few regions where a depth transect of sediment cores is available (e.g., Fig. 1 of Curry and Oppo 2005). Fourth, mixing terms in the density and transport (tracer) equations are difficult to constrain, which motivated us to represent these terms implicitly. It was suggested that in the presence of vertical mixing, the maintenance of large vertical $\delta^{13} C_{\text {DIC }}$ differences in deep water during the last glacial period implies that horizontal advection was strong (relative to vertical mixing; Curry and Oppo 2005). However, important questions remain regarding the spatial and temporal variability of mixing in the ocean. Microstructure observations suggest that the diapycnal diffusivity for buoyancy varies horizontally by two orders of magnitude at abyssal depths (e.g., Polzin et al. 1997), with important dynamical consequences (e.g., Spall 2001; Marchal and Nycander 2004). Wunsch (2003) speculated that diapycnal buoyancy mixing was enhanced in the glacial ocean due to stronger winds and elevated tidal dissipation (Egbert et al. 2004). Fifth, this work considers only two types of paleoceanographic observation. Whereas other observations are available that are presented as constraints on past ocean circulation (LynchStieglitz et al. 2007), the number of such observations is much less than the number of $\delta^{18} \mathrm{O}_{\mathrm{b}}$ and $\delta^{13} \mathrm{C}_{\mathrm{b}}$ data. Finally, the error (co)variances, which are required in any problem combining noisy data with imperfect models, involve significant arbitrariness. This state of affairs should not be taken as a weakness of inverse methods but as a statement of the difficulty to accurately estimate the error statistics of oceanographic data and models.

Acknowledgments. This work could not have been possible without the efforts of paleoceanographers to collect and analyze sediment records over about the past two decades. It is to them, collectively, that the present study is dedicated. Comments on the manuscript by two reviewers as well as Peter Huybers and Carl Wunsch have been very useful. We gratefully acknowledge discussions with various members of the scientific community, including Joël Hirschi, Peter Huybers, Pascal LeGrand, Jean Lynch-Stieglitz, Daniel McCorkle, Elisabeth Michel, and Carl Wunsch. Jean Lynch-Stieglitz and Andreas Mackensen made available to us (paleo)oceanographic data for the Little Ba- 
hama Bank and the eastern South Atlantic, respectively. The inversions reported in this work have been performed using supercomputers at the National Center for Atmospheric Research (NCAR). We thank the Computational and Information Systems Laboratory at NCAR for their technical guidance. Support for this work comes from the U.S. National Science Foundation.

\section{APPENDIX A}

\section{Difference Equations}

The differential equations of motion are discretized on a grid with a longitudinal spacing $\Delta \phi=2^{\circ}$, a latitudinal spacing $\Delta \theta=2^{\circ}$, and a vertical spacing $\Delta z_{k}$ of 1000,1250 , or $1500 \mathrm{~m}$. The difference form of the equation of volume conservation is

$$
U_{i+1, j+(1 / 2), k+(1 / 2)}-U_{i, j+(1 / 2), k+(1 / 2)}+V_{i+(1 / 2), j+1, k+(1 / 2)}-V_{i+(1 / 2), j, k+(1 / 2)}+W_{i+(1 / 2), j+(1 / 2), k+1}-W_{i+(1 / 2), j+(1 / 2), k}=\epsilon_{\mathrm{m}} .
$$

The difference analogs of the thermal wind relations are

$$
\begin{aligned}
& \overline{\Delta z_{k}}\left(\frac{V_{i, j, k+1}}{\Delta z_{k+1}}-\frac{V_{i, j, k}}{\Delta z_{k}}\right)+\left(\overline{\Delta z_{k}}\right)^{2} \frac{g}{2 \Omega \rho_{o}} \frac{\rho_{i+1, j, k+1}-\rho_{i, j, k+1}}{\sin \phi_{j}}=\epsilon_{\mathrm{v}}, \\
& \overline{\Delta z_{k}}\left(\frac{U_{i, j, k+1}}{\Delta z_{k+1}}-\frac{U_{i, j, k}}{\Delta z_{k}}\right)+\left(\overline{\Delta z_{k}}\right)^{2} \frac{g \Delta \theta}{2 \Omega \rho_{o}} \frac{\rho_{i, j+1, k+1}-\rho_{i, j, k+1}}{\left.\Delta(\cos \theta)\right|_{j} ^{j+1}}=\epsilon_{\mathrm{u}} .
\end{aligned}
$$

Here, $\overline{\Delta z_{k}}=\left(\Delta z_{k}+\Delta z_{k+1}\right) / 2, g=9.81 \mathrm{~m} \mathrm{~s}^{-2}$ is the acceleration due to gravity, $\Omega=7.29 \times 10^{-5} \mathrm{~s}^{-1}$ is the angular velocity of earth rotation, $\rho_{o}=1028 \mathrm{~kg} \mathrm{~m}^{-3}$, and $\left.\Delta(\cos \theta)\right|_{j} ^{j+1}=\cos \theta_{j+1}-\cos \theta_{j}$. The difference form of the linear vorticity equation, $(a \tan \theta)^{-1} v=\partial w / \partial z$, where $a=6371 \mathrm{~km}$ is the earth radius and $v(w)$ is the meridional (vertical) velocity, is

$$
\frac{1}{2 a}\left(\frac{v_{i+(1 / 2), j, k+(1 / 2)}}{\tan \theta_{j}}+\frac{v_{i+(1 / 2), j+1, k+(1 / 2)}}{\tan \theta_{j+1}}\right)=\frac{w_{i+(1 / 2), j+(1 / 2), k+1}-w_{i(1 / 2), j+(1 / 2), k}}{\Delta z} .
$$

Multiplying by the grid box volume $\Delta \mathcal{V}_{i, j, k}=\left.a^{2} \Delta(\sin \theta)\right|_{j} ^{j+1} \Delta \phi \Delta z_{k}$ gives

$$
\frac{\left.a \Delta(\sin \theta)\right|_{j} ^{j+1} \Delta \phi \Delta z}{2}\left(\frac{v_{i+(1 / 2), j, k+(1 / 2)}}{\tan \theta_{j}}+\frac{v_{i+(1 / 2), j+1, k+(1 / 2)}}{\tan \theta_{j+1}}\right)=\left.a^{2} \Delta(\sin \theta)\right|_{j} ^{j+1} \Delta \phi\left(w_{i+(1 / 2), j+(1 / 2), k+1}-w_{i+(1 / 2), j+(1 / 2), k}\right) .
$$

In terms of volume transport,

$$
\frac{\left.\Delta(\sin \theta)\right|_{j} ^{j+1}}{2}\left(\frac{V_{i+(1 / 2), j, k+(1 / 2)}}{\sin \theta_{j}}+\frac{V_{i+(1 / 2), j+1, k+(1 / 2)}}{\sin \theta_{j+1}}\right)-W_{i+(1 / 2), j+(1 / 2), k+1}+W_{i+(1 / 2), j+(1 / 2), k}=\epsilon_{\zeta} .
$$

Finally, the difference form of the density equation is

$$
\begin{aligned}
U_{i+1, j+(1 / 2), k+(1 / 2)} \bar{\rho}^{i+1} & -U_{i, j+(1 / 2), k+(1 / 2)} \bar{\rho}^{i}+V_{i+(1 / 2), j+1, k+(1 / 2)} \bar{\rho}^{j+1}-V_{i+(1 / 2), j, k+(1 / 2)} \bar{\rho}^{j}+W_{i+(1 / 2), j+(1 / 2), k+1} \bar{\rho}^{k+1} \\
& -W_{i+(1 / 2), j+(1 / 2), k} \bar{\rho}^{k}=F_{i, j, k+1}-F_{i, j, k}+\epsilon_{\rho} .
\end{aligned}
$$

Here, $\bar{\rho}$ is the average value of $\rho-\rho_{o}$ for a box face and $F$ is a vertical diffusive flux. The average value of $\rho-\rho_{o}$ for the western face, for example, is

$$
\bar{\rho}^{i}=\frac{1}{4}\left(\rho_{i, j, k}+\rho_{i, j+1, k}+\rho_{i, j+1, k+1}+\rho_{i, j, k+1}\right)-\rho_{o}
$$

Subtracting $\rho_{o}$ from the $\rho$ values enhances the conditioning of the system of difference equations derived from (A.1) and (A.5). The vertical diffusive flux $F$ is estimated from WOCE climatologic data using a cen- tral difference scheme for the $\rho$ gradients. For example, the flux at the lower surface of box $(i, j, k)$ is given by (WOCE values are denoted by an asterisk)

$$
F_{i, j, k}=-\frac{\rho_{o}}{g} S_{i, j} \kappa{\overline{N_{*, k}^{2}}}^{i, j},
$$

where $S_{i, j}=\left.a^{2} \Delta(\sin \theta)\right|_{j} ^{j+1} \Delta \phi$ is the horizontal surface area of the box, $\kappa=10^{-4} \mathrm{~m}^{2} \mathrm{~s}^{-1}$ is an apparent diffusivity for buoyancy (e.g., Munk and Wunsch 1998), and $z_{*, k-1}$ is the square of the buoyancy frequency averaged over the surface; that is, 


$$
N_{*, k}^{2}=\frac{g}{z_{*, k-1}-z_{*, k+1}} \ln \frac{\rho_{*, k-1}}{\rho_{*, k+1}}-\left(\frac{g}{c_{*, k}}\right)^{2}
$$

Here, $\rho_{*, k-1}$ and $\rho_{*, k+1}$ are the in situ densities at the climatologic grid depths $z_{*, k-1}$ and $z_{*, k+1}$, respectively, and $c_{*, k}$ is the sound speed at the climatologic grid depth $z_{*, k}$ computed from in situ temperature, salinity, and pressure (Chen and Millero 1977). For example, if the lower surface of the box is at $z_{k}=2500 \mathrm{~m}, z_{*, k+1}$ (directly above $z_{k}$ ) is $2250 \mathrm{~m}$ and $z_{*, k-1}$ (directly below $z_{k}$ ) is $2750 \mathrm{~m}$ (Gourestki and Koltermann 2004).
Two comments are noteworthy regarding the density fluxes in (A.5). First, our representation of the diffusive fluxes (A.6)-(A.7) implies that they are entirely imposed. The variables $\rho$ at model grid points do not appear in this representation, so that these fluxes are not altered by the minimization of the cost $I$. Second, the advective and diffusive fluxes are assumed to vanish at the bottom $(2500,3750$, or $4750 \mathrm{~m})$. The $W$ values carried by the bottom grid points are fixed to zero and are excluded from the state $\mathbf{x}$.

Consider, finally, the difference forms of the transport Eqs. (10) and (14). The difference form of (10) is

$$
\begin{aligned}
U_{i+1, j+(1 / 2), k+(1 / 2)} \bar{\delta}^{i+1} & -U_{i, j+(1 / 2), k+(1 / 2)} \bar{\delta}^{i}+V_{i+(1 / 2), j+1, k+(1 / 2)} \bar{\delta}^{j+1}-V_{i+(1 / 2), j, k+(1 / 2)} \bar{\delta}^{j}+W_{i+(1 / 2), j+(1 / 2), k+1} \bar{\delta}^{k+1} \\
& -W_{i+(1 / 2), j+(1 / 2), k} \bar{\delta}^{k}=\epsilon_{\mathrm{O}}
\end{aligned}
$$

where $\delta \equiv \delta^{18} \mathrm{O}_{\mathrm{c}}$. The difference form of (14) is

$$
\begin{aligned}
U_{i+1, j+(1 / 2), k+(1 / 2)} \bar{\delta}^{i+1} & -U_{i, j+(1 / 2), k+(1 / 2)} \bar{\delta}^{i}+V_{i+(1 / 2), j+1, k+(1 / 2)} \bar{\delta}^{j+1}-V_{i+(1 / 2), j, k+(1 / 2)} \bar{\delta}^{j}+W_{i+(1 / 2), j+(1 / 2), k+1} \bar{\delta}^{k+1} \\
& -W_{i+(1 / 2), j+(1 / 2), k} \bar{\delta}^{k}-J_{*, \delta} \Delta \mathcal{V}_{i, j, k}=\epsilon_{\mathrm{C}}
\end{aligned}
$$

Here, $\delta \equiv \delta^{13} \mathrm{C}_{\mathrm{DIC}}$ and

$$
J_{*, \delta}=J_{*}\left(\delta_{\text {org }}-\frac{\delta_{i, j, k}+\delta_{i, j+1, k}+\delta_{i, j+1, k+1}+\delta_{i, j, k+1}+\delta_{i+1, j, k}+\delta_{i+1, j+1, k}+\delta_{i+1, j+1, k+1}+\delta_{i+1, j, k+1}}{8}\right),
$$

where $\delta_{\text {org }} \equiv \delta^{13} \mathrm{C}_{\text {org }}$. The residuals $\left(\epsilon_{\mathrm{O}}, \epsilon_{\mathrm{C}}\right)$ should account for the errors associated with the omission of mixing, the assumptions about $\left(J_{*}, \delta^{13} \mathrm{C}_{\text {org }}\right)$, and the discretization (sections $4 \mathrm{~d}$ and $5 \mathrm{~d}$ ).

The quantities $J_{*}$ and $\delta^{13} \mathrm{C}_{\text {org }}$ are estimated as follows: the rates of remineralization (biological respiration) below $1000 \mathrm{~m}$ are often extremely low and few direct measurements are available. According to the review of Del Giorgio and Duarte (2002, their Table 1), the global respiration below $1000 \mathrm{~m}$ amounts to 1.3-1.6 $\mathrm{Gt} \mathrm{C} \mathrm{yr}{ }^{-1}\left(1 \mathrm{Gt}=10^{15} \mathrm{~g}\right)$. Assuming an oceanic volume deeper than $1000 \mathrm{~m}$ of $1 \times 10^{18} \mathrm{~m}^{3}$, a global rate of 1.5 $\mathrm{Gt} \mathrm{C} \mathrm{yr}^{-1}$ would correspond to a volumetric rate averaging $1.2 \times 10^{-4} \mathrm{~mol} \mathrm{C} \mathrm{m}^{-3} \mathrm{yr}^{-1}$. Dividing this latter value by the concentration of DIC in seawater of $\sim 2$ mol C m ${ }^{-3}$ yields our selected value $J_{*}=0.6 \times 10^{-4}$ $\mathrm{yr}^{-1}$. Likewise, a constant $\delta^{13} \mathrm{C}_{\mathrm{org}}=-20 \%$, which is a plausible average (e.g., Goericke and Fry 1994), is adopted.

\section{APPENDIX B}

\section{Comparison to Earlier Flow Estimates}

This appendix summarizes earlier estimates of the time-mean flow in the deep Atlantic at resolution(s) comparable to ours obtained using inverse methods
(Olbers et al. 1985; Martel and Wunsch 1993; Mercier et al. 1993). Results derived from the inversion of hydrographic sections using box models or time-dependent flows estimated from general circulation models constrained by observations are not considered here. Note that several factors limit the comparability of flow estimates inferred in different studies. For example, varying hydrographic data and/or dynamical constraints have been employed. The use of different spatial resolutions implies that comparing circulation schemes inferred in different studies is also delicate. Finally, the studies listed above were restricted to the Northern Hemisphere, whereas our domain of investigation extends to $46^{\circ} \mathrm{S}$.

Olbers et al. (1985) used the $\beta$-spiral technique to combine climatologic data of $(T, S)$ at $1^{\circ}$ resolution with formal constraints provided by the thermal wind and the statements for heat and salt conservation. The dominant feature in the horizontal circulations at 2000 and $1500 \mathrm{~m}$ is a western boundary current flowing southward; in the interior, regions of strong currents alternate with almost motionless water and the flow field lacks of an apparent large-scale coherence (Figs. 17a, b of Olbers et al. 1985). Recirculation structures just east of the boundary current, however, are suggested. 
Mercier et al. (1993) used surface drifter and SOFAR float trajectories with hydrographic data, wind data, and the constraints from a nonlinear geostrophic model. The model domain has a resolution of $2^{\circ}$ latitude and $2.5^{\circ}$ longitude. The mass, heat, and salt conservations are applied in a vertically integrated form (from the sea surface to floor). The inferred circulation exhibits a deep western boundary current along a meridional section at $53.75^{\circ} \mathrm{W}$ and along a zonal section at $29^{\circ} \mathrm{N}$ (see, respectively, Figs. 26b, 27 of Mercier et al. 1993).

Martel and Wunsch (1993) combined diverse datasets with the constraints from a linear geostrophic model. The database includes, for example, observations of $(T, S)$, current meter and float records, measurements of dissolved oxygen and nutrients, as well as certain integral fluxes. The model resolution is $1^{\circ}$ at best and is much coarser in many aspects. The "basic solution" (which actually excludes some of the data listed above) shows a western boundary current at 3000 dbar (Fig. 8 of Martel and Wunsch 1993). At 2000 dbar, this current clearly appears along the continental slope but weakens at $36^{\circ} \mathrm{N}$ (their Fig. 13). Coherent features are also present in the interior. At 2000 dbar, the northeastern basin is characterized by a southward flow originating from the Norwegian Sea outflow at $60^{\circ} \mathrm{N}$, part of it is turning around $30^{\circ} \mathrm{N}$ toward the western basin (their Fig. 13). The pattern at 2000 dbar is different from the one inferred by Olbers et al. (1985), which does not include such a strong Norwegian Sea outflow and consists instead in a broad, smooth western boundary current. At $3000 \mathrm{dbar}$, the flow is similar to the one at $2000 \mathrm{dbar}$ - southward in both basins and along the ridge (Fig. 14 of Martel and Wunsch 1993). Water from the Norwegian Sea outflow is spreading into the western basin. Finally, at 4000 dbar, the flow also is generally southward albeit much slower (their Fig. 15A). There is, however, an indication of a northward flow on the western and eastern sides of the ridge between $18^{\circ}$ and $30^{\circ} \mathrm{N}$.

\section{APPENDIX C}

\section{Oceanic Representativity of $\delta^{18} O_{b}$ and $\delta^{13} C_{b}$}

Our compilation includes $\delta^{18} \mathrm{O}$ and $\delta^{13} \mathrm{C}$ data for several species of the Cibicidoides and Planulina taxonomic groups from cores with very different abundances of benthic foraminiferal tests and with different environmental conditions. Consider the $\delta^{18} \mathrm{O}_{\mathrm{b}}$ data used to produce the multiple regression (1). LynchStieglitz et al. (1999) published $\delta^{18} \mathrm{O}$ from Cibicidoides and Planulina collected over a $5^{\circ}$ to $25^{\circ} \mathrm{C}$ temperature range on Little Bahama Bank. The measurements were made on individual tests, multiple measurements for each species were made, and several species at each depth and temperature were analyzed. By comparing the variability within these various types of data, we place constraints on the uncertainty of the analytical methods. The multiple regression for measurements of individual tests and including all Cibicidoides and Planulina species yields an rms error for $\delta^{18} \mathrm{O}_{\mathrm{b}}$ of $0.25 \%$. When the individual test measurements are averaged for each species, this error is reduced to $0.18 \%$ [ [this is the regression presented in Eq. (1)]. For each of the two regressions, the regression coefficients are indistinguishable. If we consider just one species (Cibidicoides pachyderma), the rms error for $\delta^{18} \mathrm{O}_{\mathrm{b}}$ amounts to $0.21 \%$ for the individual tests and to $0.14 \%$ or for averages of the individual tests. Again, the regression coefficients are indistinguishable from each other and also indistinguishable from the multiple (mixed) species regression. In each case, variability within a species (i.e., variability among individual tests in a sample) is large enough to introduce significant uncertainty. Thus the sample size of the measurements is key to producing a reliable estimate of benthic $\delta^{18} \mathrm{O}$. Because our compiled data (Fig. 3) come from sources using many different Cibicidoides and Planulina species and because, for the most part, the measurements were made on samples consisting of several tests (grouped together in one measurement rather than as individuals in the example above), we believe that the rms error of $0.18 \%$ is the most appropriate estimate of the uncertainty in the compiled $\delta^{18} \mathrm{O}_{\mathrm{b}}$ data. However, because the data come from many different laboratories, the actual uncertainty must be higher. It is unlikely, given the current state of analytical capabilities, that the uncertainty in $\delta^{18} \mathrm{O}_{\mathrm{b}}$ will be much lower than $0.14 \%$, which is the value for a single species with large numbers of individuals available for measurement and with all measurements performed in the same laboratory.

Note that measurements of $\delta^{18} \mathrm{O}$ on "live" (RoseBengal stained) benthic foraminifera tend to exhibit large variability. The difference $\left(\Delta \delta^{18} \mathrm{O}\right)$ between $\delta^{18} \mathrm{O}$ of Cibicidoides from surface sediments and $\delta^{18} \mathrm{O}$ of equilibrium calcite for ambient bottom water has been observed to vary over a range of $\sim 1 \%$ in the eastern North Atlantic (McCorkle and Holder 2001). This large range is consistent with the range of $\delta^{18} \mathrm{O}$ seen in the individual tests at Little Bahama Bank at a single temperature (Lynch-Stieglitz et al. 1999) and probably results from the small number of live specimens making up each analysis. More consistent $\Delta \delta^{18} \mathrm{O}$ values (varying within a range of ca. $0.5 \%$ ) have been found at the Sierra Leone Rise and the Cape Verde Plateau (Mc- 
Corkle and Holder 2001). Unfortunately, very few $\delta^{18} \mathrm{O}$ measurements on live benthic foraminifera are available for comparison.

The uncertainty in the oceanic representativity of $\delta^{13} \mathrm{C}_{\mathrm{b}}$ appears on average lower than for $\delta^{18} \mathrm{O}_{\mathrm{b}}$. Many of the same sources of error exist, with the exception that instrumental errors are not much of a problem (Ostermann and Curry 2000). According to a "global" calibration (Duplessy et al. 1984), the difference $\left(\Delta \delta^{13} \mathrm{C}\right)$ between $\delta^{13} \mathrm{C}$ of Cibicidoides shells from surface sediments and $\delta^{13} \mathrm{C}_{\text {DIC }}$ of ambient bottom water averages $0.07 \pm 0.04 \%$ (two standard errors). More recent measurements on live benthic foraminifera support this result for C. wuellerstorfi (McCorkle and Holder 2001), a species commonly measured in glacial sediments. Sarnthein et al. (1994) stated that $\Delta \delta^{13} \mathrm{C}$ is generally less than $\pm 0.2 \%$ in the eastern Atlantic, but they did not provide an estimate of the statistical dispersion of this value. On the other hand, larger values have been reported at some locations. McCorkle and Holder (2001) observed that $\Delta \delta^{13} \mathrm{C}$ values in the eastern North Atlantic and at the Ceara Rise are generally consistent with the global average of Duplessy et al. (1984), although for some samples much larger offsets $(>0.5 \%$ ) occur there as well as at other locations ( $\mathrm{Si}$ erra Leone Rise and Cape Verde Plateau). Oppo and Horowitz (2000) reported $\Delta \delta^{13} \mathrm{C}$ values up to $0.4 \%$ at Antarctic Intermediate Water depths in the western Atlantic near $30^{\circ} \mathrm{S}$. Although $\Delta \delta^{13} \mathrm{C}$ appears generally positive, negative offsets have been observed at some locations. Mackensen et al. (1993) estimated that $\Delta \delta^{13} \mathrm{C}$ averages $-0.2 \%$ with minima ranging from -0.8 to $-0.9 \%$ south of $\sim 40^{\circ} \mathrm{S}$ in the eastern Atlantic.

\section{REFERENCES}

Adkins, J. F., K. McIntyre, and D. P. Schrag, 2002: The salinity, temperature, and $\delta^{18} \mathrm{O}$ of the glacial deep ocean. Science, $\mathbf{2 9 8 ,}$ 1769-1773.

Bainbridge, A. E., 1981: GEOSECS Atlantic expeditions. Hydrographic Data 1972-1973, Vol. 1, International Decade of Ocean Exploration, National Science Foundation, 121 pp.

Baringer, M., and J. Price, 1997: Mixing and spreading of the Mediterranean Outflow. J. Phys. Oceanogr., 27, 1654-1677.

Bickert, T., and A. Mackensen, 2003: Late Glacial to Holocene changes in South Atlantic deep water circulation. The South Atlantic in the Late Quaternary-Reconstruction of Material Budget and Current Systems, G. Wefer, S. Mulitza, and V. Rathmeyer, Eds., Springer-Verlag, 671-693.

Bigg, G. R., and E. J. Rohling, 2000: An oxygen isotope data set for marine waters. J. Geophys. Res., 105, 8527-8535.

Boyle, E. A., 1992: Cadmium and $\delta^{13} \mathrm{C}$ paleochemical ocean distributions during the stage 2 glacial maximum. Annu. Rev. Earth Planet. Sci., 20, 245-287.

Bretherton, F. P., R. E. Davis, and C. B. Fandry, 1976: A tech- nique for objective analysis and design of oceanographic experiments applied to MODE-73. Deep-Sea Res., 23, 559-582.

Bryden, H. L., H. R. Longworth, and S. A. Cuningham, 2005: Slowing of the Atlantic meridional overturning circulation at $25^{\circ} \mathrm{N}$. Nature, 438, 655-657, doi:10.1038/nature04385.

Chen, C.-T., and F. J. Millero, 1977: Speed of sound in seawater at high pressures. J. Acoust. Soc. Amer., 62, 1129-1135.

Clark, P. U., and A. C. Mix, 2002: Ice sheets and sea level of the Last Glacial Maximum. Quat. Sci. Rev., 21, 1-7.

Curry, W. B., and D. W. Oppo, 2005: Glacial water mass geometry and the distribution of $\delta^{13} \mathrm{C}$ of $\Sigma \mathrm{CO}_{2}$ in the Western Atlantic Ocean. Paleoceanography, 20, PA1017, doi:10.1029/ 2004PA001021.

Del Giorgio, P. A., and C. M. Duarte, 2002: Respiration in the open ocean. Nature, 420, 379-384.

Duplessy, J.-C., 1972: La géochimie des isotopes stables du carbone dans la mer. Ph.D Note CEA-N-1565, Centre d'Etudes Nucléaires de Saclay, 40-50.

—, N. J. Shackleton, R. K. Matthews, W. Prell, W. F. Ruddiman, M. Caralp, and C. H. Hendy, $1984:{ }^{13} \mathrm{C}$ record of benthic foraminifera in the last interglacial ocean: Implications for the carbon cycle and the global deep water circulation. Quat. Res., 21, 225-243.

Egbert, G. D., R. D. Ray, and B. G. Bills, 2004: Numerical modeling of the global semidiurnal tide in the present day and in the last glacial maximum. J. Geophys. Res., 109, C03003, doi:10.1029/2003JC001973.

Gebbie, J., and P. Huybers, 2006: Meridional circulation during the Last Glacial Maximum explored through a combination of South Atlantic $\delta^{18} \mathrm{O}$ observations and a geostrophic inverse model. Geochem. Geophys. Geosys., 7, Q11N07, doi:10.1029/2006GC001383.

Goericke, R., and B. Fry, 1994: Variations of marine plankton $\delta^{13} \mathrm{C}$ with latitude, temperature, and dissolved $\mathrm{CO}_{2}$ in the world ocean. Global Biogeochem. Cycles, 8, 85-90.

Gourestki, V. V., and K. P. Koltermann, 2004: WOCE global hydrographic climatology: A technical report. Berichte des Bundesamtes für Seeschifffahrt und Hydrographie 35, 52 pp. and two CD-ROMS.

Hall, M. M., M. McCartney, and J. A. Whitehead, 1997: Antarctic Bottom Water flux in the equatorial western Atlantic. $J$. Phys. Oceanogr., 27, 1903-1926.

Hirschi, J. J.-M., and J. Lynch-Stieglitz, 2006: Ocean margin densities and paleoestimates of the Atlantic meridional overturning circulation: A model study. Geochem. Geophys. Geosys., 7, Q10N04, doi:10.1029/2006GC001301.

Hogg, N., 1983: A note on the deep circulation of the western North Atlantic: Its nature and causes. Deep-Sea Res., 30, 945961.

— R. R. Pickart, R. M. Hendry, and W. J. Smethie, 1986: The Northern recirculation gyre of the Gulf Stream. Deep-Sea Res., 33, 1139-1165.

— G. Siedler, and W. Zenk, 1999: Circulation and variability at the southern boundary of the Brazil Basin. J. Phys. Oceanogr., 29, 145-157.

Huybers, P., J. Gebbie, and O. Marchal, 2007: Can paleoceanographic tracers constrain meridional circulation rates? $J$. Phys. Oceanogr., 37, 394-407.

Kroopnick, P. M., 1985: The distribution of ${ }^{13} \mathrm{C}$ of $\mathrm{TCO}_{2}$ in the world oceans. Deep-Sea Res., 32, 57-84.

LeGrand, P., and C. Wunsch, 1995: Constraints from paleotracer data on the North Atlantic circulation during the last glacial maximum. Paleoceanography, 10, 1011-1045. 
Lumpkin, R., and K. Speer, 2003: Large-scale vertical and horizontal circulation in the North Atlantic Ocean. J. Phys. Oceanogr., 33, 1902-1920.

Lynch-Stieglitz, J., W. B. Curry, and N. Slowey, 1999: A geostrophic transport estimate for the Florida Current from oxygen isotope composition of benthic foraminifera. Paleoceanography, 14, 360-373.

_ , and Coauthors, 2007: Atlantic meridional overturning circulation during the Last Glacial Maximum. Science, 316, 6669.

Mackensen, A., H.-W. Hubberten, T. Bickert, G. Fisher, and D. K. Fütterer, 1993: The $\delta^{13} \mathrm{C}$ in benthic foraminiferal tests of Fontbotia wuellerstorfi (Schwager) relative to the $\delta^{13} \mathrm{C}$ of dissolved inorganic carbon in Southern Ocean deep water: Implications for glacial ocean circulation models. Paleoceanography, 8, 587-610.

Marchal, O., and J. Nycander, 2004: Nonuniform upwelling in a shallow-water model of the Antarctic Bottom Water in the Brazil Basin. J. Phys. Oceanogr., 34, 2492-2513.

- R. François, and J. Scholten, 2007: Contribution of ${ }^{230} \mathrm{Th}$ measurements to the estimation of the abyssal circulation. Deep-Sea Res., 54, 557-585.

Martel, F., and C. Wunsch, 1993: The North Atlantic circulation in the early $1980 \mathrm{~s}$-An estimate from inversion of a finitedifference model. J. Phys. Oceanogr., 23, 898-924.

McCartney, M. S., and R. A. Curry, 1993: Transequatorial flow of Antarctic Bottom Water in the western Atlantic Ocean: Abyssal geostrophy at the equator. J. Phys. Oceanogr., 23, 1264-1276.

McCorkle, D. C., and A. L. Holder, 2001: Calibration studies of deep-sea benthic foraminiferal isotopic composition: Results from the southeast Pacific. Eos, Trans. Amer. Geophys. Union, 82, 473.

Mercier, H., 1986: Determining the general circulation of the ocean: A nonlinear inverse problem. J. Geophys. Res., 91, 5103-5109.

_ , and K. Speer, 1998: Transport of bottom water in the Romanche Fracture Zone and the Chain Fracture Zone. J. Phys. Oceanogr., 28, 779-790.

_ M. Ollitraut, and P. Y. Le Traon, 1993: An inverse model of the North Atlantic general circulation using Lagrangian float data. J. Phys. Oceanogr., 23, 689-715.

Munk, W., and C. Wunsch, 1998: Abyssal recipes II: Energetics of tidal and wind mixing. Deep-Sea Res., 45, 1977-2010.

Ochoa, J., and N. A. Bray, 1991: Water mass exchange in the Gulf of Cadiz. Deep-Sea Res., 38, 465-503.

Olbers, D. J., M. Wenzel, and J. Willebrand, 1985: The inference of North Atlantic circulation patterns from climatological hydrographic data. Rev. Geophys., 23, 313-356.

Oppo, D. W., and M. Horowitz, 2000: Glacial deep water geometry: South Atlantic benthic foraminiferal $\mathrm{Cd} / \mathrm{Ca}$ and $\delta^{13} \mathrm{C}$ evidence. Paleoceanography, 15, 147-160.

Ostermann, D. R., and W. B. Curry, 2000: Calibration of stable isotope data: An enriched $\delta^{18} \mathrm{O}$ standard use for source gas mixing detection and correction. Paleoceanography, 15, 353360.

Ostlund, H. G., H. Craig, W. S. Broecker, and D. Spencer, 1987: GEOSECS Atlantic, Pacific, and Indian ocean expeditions.
Shore-based Data and Graphics, Vol. 7, International Decade of Ocean Exploration, National Science Foundation, 200 pp. Pedlosky, J., 1996: Ocean Circulation Theory. Springer, 453 pp.

Polzin, K. L., J. M. Toole, J. R. Ledwell, and R. W. Schmitt, 1997: Spatial variability of turbulent mixing in the abyssal ocean. Science, 276, 93-96.

Roemmich, D., and C. Wunsch, 1985: Two transatlantic sections: Meridional circulation and heat flux in the subtropical North Atlantic Ocean. Deep-Sea Res., 32, 619-664.

Sarnthein, M., K. Winn, S. J. A. Jung, J.-C. Duplessy, L. Labeyrie, H. Erlenkeuser, and G. Ganssen, 1994: Changes in east Atlantic deepwater circulation over the last 30000 years: Eight time slice reconstructions. Paleoceanography, 9, 209-267.

Schmitz, W. J., 1995: On the interbasin-scale thermohaline circulation. Rev. Geophys., 33, 151-173.

—, 1996: On the World Ocean Circulation. Vol. 1. Some Global Features/North Atlantic Circulation, Woods Hole Oceanographic Institution Tech. Rep. WHOI-96-03, 141 pp.

Schrag, D., J. F. Adkins, K. McIntyre, J. L. Alexander, D. A. Hodell, C. D. Charles, and J. F. McManus, 2002: The oxygen isotopic composition of seawater during the Last Glacial Maximum. Quat. Sci. Rev., 21, 331-342.

Spall, M. A., 2001: Large-scale circulations forced by localized mixing over a sloping bottom. J. Phys. Oceanogr., 31, 23692384.

Talley, L. D., 2003: Shallow, intermediate, and deep overturning components of the global heat budgets. J. Phys. Oceanogr., 33, 530-560.

Tarantola, A., and B. Valette, 1982: Generalized nonlinear inverse problem solved using the least squares criterion. Rev. Geophys. Space Phys., 20, 219-232.

Vanicek, M., and G. Siedler, 2002: Zonal fluxes in the deep water layers of the western south Atlantic Ocean. J. Phys. Oceanogr., 32, 2205-2235.

Winguth, A. M. E., D. Archer, E. Maier-Reimer, and U. Mikolajewicz, 2000: Paleonutrient data analysis of the glacial Atlantic using an adjoint ocean general circulation model. Inverse Methods in Global Biogeochemical Cycles, Vol. 114, Geophys. Monogr., Amer. Geophys. Union, 171-183.

Wunsch, C., 1996: The Ocean Circulation Inverse Problem. Cambridge University Press, 442 pp.

_ 2003: Determining paleoceanographic circulations, with emphasis on the Last Glacial Maximum. Quat. Sci. Rev., 22, 371-385.

Zahn, R., and A. Mix, 1991: Benthic foraminiferal $\delta^{18} \mathrm{O}$ in the ocean's temperature-salinity-density field: Constraints on ice age thermohaline circulation. Paleoceanography, 6, 1-20.

_- M. Sarnthein, and H. Erlenkeuser, 1987: Benthic isotope evidence for changes of the Mediterranean Outflow during the Late Quaternary. Paleoceanography, 2, 543-559.

—, J. Schönfeld, H.-R. Kudrass, M.-H. Park, H. Erlenkeuser, and P. Grootes, 1997: Thermohaline instability in the North Atlantic during meltwater events: Stable isotope and icerafted detritus records from core SO75-26KL, Portuguese margin. Paleoceanography, 12, 696-710.

Zenk, W., G. Siedler, B. Lenz, and N. Hogg, 1999: Antarctic Bottom Water flow through the Hunter Channel. J. Phys. Oceanogr., 29, 2785-2801. 